
19 0

\title{
Water quality mediated resilience on the Great Barrier Reef
}

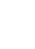

M Aaron MacNeil ${ }^{\mathrm{a}}$, Camille Mellin's,c, Sam Matthews ${ }^{\mathrm{b}, \mathrm{d}}$, Nicholas H. Wolff ${ }^{\mathrm{f}}$, Timothy R. McClanahan ${ }^{\mathrm{g}}$, Michelle Devlin $^{\mathrm{h}}$, Christopher Drovandi ${ }^{\mathrm{ij}}$, Kerrie Mengersen ${ }^{\mathrm{ij}}$, and Nicholas AJ Graham $^{\mathrm{k}}$ (1)

${ }^{\mathrm{a} D e p a r t m e n t ~ o f ~ B i o l o g y, ~ D a l h o u s i e ~ U n i v e r s i t y, ~ H a l i f a x ~ N S ~ B 3 H ~ 4 R 2, ~ C a n a d a ; ~}{ }^{\mathrm{b}}$ Australian Institute of Marine Science, PMB 3 Townsville MC, Townsville, QLD 4810, Australia; ${ }^{\circ}$ The Environment Institute and School of Biological Sciences, University of Adelaide, South Australia 5005, Australia; dARC Centre of Excellence in Coral Reef Studies, James Cook University,

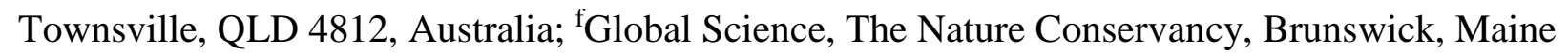

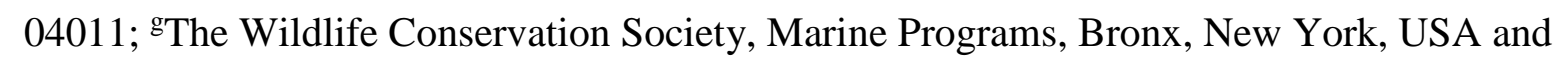
Marine Programs, Mombasa, Kenya; ${ }^{\mathrm{h} C e n t r e ~ f o r ~ E n v i r o n m e n t, ~ F i s h e r i e s ~ a n d ~ A q u a c u l t u r e ~}$ Science, Lowestoft Laboratory, Lowestoft, NR33 0HT, UK; 'iSchool of Mathematical Sciences, Queensland University of Technology, Brisbane, QLD, Australia; ${ }^{j}$ Australian Centre of Excellence for Mathematical and Statistical Frontiers, Brisbane, QLD, Australia; ${ }^{\text {Lancaster }}$ Environment Centre, Lancaster University, Lancaster LA1 4YQ, UK. 
21 Threats from climate change and other human pressures have led to widespread 22 concern for the future of Australia's Great Barrier Reef (GBR) ${ }^{1}$, where increasingly

23 frequent and severe coral bleaching, fishing, and ongoing pollution are

24 undermining long-term persistence of coral-dominated reefs ${ }^{2,3}$. Future resilience

25 of coral-dominated reefs within the GBR will be determined by their ability to

26 resist disturbances and to recover from coral loss, generating intense interest in

27 management actions that can moderate these processes ${ }^{4-7}$. Here we quantify the

28 effect of environmental and human drivers on the resistance and recovery of hard

29 corals to multiple disturbances within the southern and central GBR. Using a

30 composite index for water quality, we find that reefs exposed to poor water quality

31 recover from disturbance more slowly and are more susceptible to outbreaks of

32 crown-of-thorns starfish and coral disease while also being more resistant to

33 coral bleaching. Protection from fishing and increased herbivory were not

34 associated with substantially faster recovery from disturbance. Water quality

35 mediation of a tradeoff between resistance and recovery illustrates that, while reefs in waters of chronically-poor quality contain corals with greater bleaching

37 resistance, there is a net negative impact on recovery and long-term hard coral cover. Given these conditions, we find that $11-23 \%$ improvements in water quality will be necessary to bring recovery rates in line with projected increases in coral bleaching among contemporary inshore and mid-shelf reefs. However such

41 reductions are unlikely to buffer projected bleaching effects among outer-shelf 
47 The Great Barrier Reef (GBR) has experienced unprecedented losses of hard coral cover ${ }^{8}$. Most

GBR reefs dominated by fast growing, thermally sensitive corals, demonstrating practical limits to local management of the GBR against the effects of global warming. coral loss on the GBR has been due to acute disturbances including storms ${ }^{9,10}$, disease ${ }^{11}$, outbreaks of crown-of-thorns starfish Acanthaster spp. (CoTS) ${ }^{9}$, and coral bleaching ${ }^{8}$. Many of these impacts are predicted to become more frequent or intense due to climate change ${ }^{2,10,12-14}$. Key to long-term coral-dominance on reefs is whether coral communities can resist coral loss and recover sufficiently quickly between successive disturbances to be resilient and sustain viable populations ${ }^{15}$. However, there are currently few process-based models for quantifying intrinsic rates of increase that accurately characterize recovery. Some of the key drivers thought to influence coral cover recovery include rates of herbivory ${ }^{16}$, coral community composition ${ }^{17,18}$, water quality $^{19-22}$, and protection from fishing ${ }^{23}$. While research into individual drivers is well developed, how cumulative stressors may interact under climate change is not; the potential for non-linear responses to novel ecosystem states creates considerable uncertainty in predicting future coral reef states ${ }^{24}$.

A key question facing many reefs world-wide is the nature of the relationship between long-term anthropogenic pollution loads and the resilience of coral reefs, which underpins millions of 
63 dollars in public and private remediation investment ${ }^{25}$. Changes in water quality, such as

64 increases in dissolved nutrients and fine sediment associated with changes in land use have been

65 linked to increases in algal densities ${ }^{26}$, changes in coral community composition ${ }^{21}$, and outbreaks 66 of coral predators ${ }^{27}$ and disease ${ }^{28}$. Yet despite experimental ${ }^{29}$ and observational evidence ${ }^{30}$, the 67 potentially widespread role of deteriorating water quality in specifically regulating reef recovery 68 rates is not well known. Setting targets for specific water quality parameters such as sediments 69 and nutrient loads need to be appropriate to meet ecologically relevant targets that support ecosystem objectives and untangle the effects of multiple sources of disturbance from associated 71 environmental and management drivers of reef resilience ${ }^{31}$.

73 To quantify the effects of varying disturbance and ecosystem properties on coral reef resilience, 74 we developed a Gompertz-based Bayesian hierarchical model for spatial coverage of hard coral 75 cover ${ }^{32}$ within the central and southern sectors of world's largest coral reef ecosystem, Australia's 76 GBR. Defining resilience as the sum of resistance (ability to limit coral loss due to acute 77 disturbance) and recovery (rate at which coral returns to pre-disturbance levels) ${ }^{33}$, we used surveys of coral cover from 46 reefs between 1995 and 2017, that use replicate fixed-transects particularly suited to quantifying localized and long-term coral cover dynamics ${ }^{34}$. Importantly, 80 during the time period under study, these reefs have been influenced by a number of major 81 disturbances ${ }^{11}$, including tropical cyclones ${ }^{10}$, CoTS outbreaks ${ }^{35}$, coral diseases ${ }^{28}$, and severe 82 bleaching ${ }^{8}$. These disturbances reduced coral cover by varying degrees, while subsequent 83 monitoring has captured reef recovery ${ }^{36}$. Within four characteristic community types ${ }^{37}$ (Extended 
84 Data Fig 1) we quantified four key properties thought to influence resistance and recovery:

85 protection from fisheries, coral community composition, herbivore density, and water quality.

86 Herbivore density and coral community composition were estimated directly from the monitoring

87 data, while fisheries protection (both no-take or no-entry) was defined by the Great Barrier Reef

88 Marine Park Zoning Plan ${ }^{38}$. Water quality was defined as a metric that encompassed several

89 water quality issues including fine sediment associated turbidity and high nutrient waters

90 supporting high phytoplankton biomass measured as chlorophyll typically associated with the

91 input and extent of river plumes in the wet season. The "water quality" metric is captured as the

92 average frequency of exposure to river-influenced plumes $\left(\mathrm{PF}_{\mathrm{C}}\right)$, which includes the average

93 frequency of highly turbid (primary), high chlorophyll-a (secondary), and colored dissolved

94 organic matter (tertiary) water masses ${ }^{39}$ (see Supplemental Methods). As such, PFc represents an

95 assessment of reduced water quality conditions in the wet season. Our approach is unique in

96 explicitly representing potential effects of a range of conditions on the recovery rate of corals

97 within a mechanistic population model. Thus, with a strong set of concurrent empirical data, we

98 were able to model the resilience history of a large portion of GBR and estimate how it can be

99 expected to respond to increasingly frequent thermal stress.

100

101 In 1995 and 2017, average coral cover was comparable (from 28\% to 29\%), with substantial

102 periods of decline and recovery (Fig 1) including expected average coral cover levels between

103 18\% and 56\% (Figs 1b, 2b). Among known disturbances at locations with long term monitoring

104 (see Extended Data), storms had the largest impact on coral cover (-0.22 [-1.84, 1.65]; posterior 
105

median and 95\% highest posterior density interval for standardized effect sizes) followed by CoTS $(-0.20[-0.55,0.08])$, bleaching $(-0.10[-0.12,-0.08])$, and coral disease $(-0.02$ [-0.03, 0.0]), with evidence of more intense storm impacts along the outer shelf, and greater hard coral losses from CoTS among Poritidae/Alcyoniidae and Acropora-dominated reefs (Fig 2e).

Resistance to disturbance was also adversely impacted by increasing exposure to the riverine plume waters, measured by an increasing $\mathrm{PF}_{\mathrm{C}}$ value and associated with greater hard coral loss from both CoTS and disease (Fig 2f), strongly supporting the assumed role of elevated nutrients increasing both CoTS larval survival ${ }^{27,41}$ and disease prevalence ${ }^{21,42}$.

In addition to these adverse impacts of exposure to high nutrient, high turbidity riverine flood plumes, we also found that the frequency of exposure to river-influenced plumes has led to increased coral resistance during thermal stress and bleaching events among inshore reefs. Although bleaching on the GBR typically occurs during doldrum conditions when sediment particles are likely to settle, high turbidity waters associated with riverine plume waters reduce exposure to light stress and hence the probability of a bleaching response where corals expel their algal symbionts ${ }^{43}$. In addition, the extreme environmental conditions characteristic of inshore settings (e.g. chronic runoff exposure, fluctuating turbidity, light, and temperatures) have shifted coral community composition at some locations toward more disturbance-tolerant species ${ }^{44}$, allowing these communities to tolerate thermal anomalies better than those in the more stable thermal conditions of offshore reefs ${ }^{45,46}$. This increased resistance to bleaching appears to offset some of the obvious negative impacts from elevated nutrient concentrations delivered in riverine 
126 plume waters ${ }^{47,48}$, although these effects are likely overwhelmed by the most extreme warming

127 conditions such as those observed in 2016/2017. The major coral bleaching and mortality event in

128 2015-2016 and 2016-2017 severely impacted reefs world-wide ${ }^{2,8}$, with extensive losses of hard

129 coral that transformed coral reef assemblages across the northern (2015-2016) and central (2016-

130 2017) Great Barrier Reef ${ }^{1}$. Readers may therefore be surprised that coral bleaching did not

131 feature as the most prominent source of disturbance in our analysis. However this bleaching event

132 was unique in the recorded history of the GBR in that it occurred primarily in the northernmost

133 sector, long considered the 'pristine' end of the reef ${ }^{1}$ and where limited long-term monitoring

134 data exists.

135

136 Following disturbance, we found that coral recovery was most rapid among the Acropora-

137 dominated reefs that span the outer shelf (Fig 2a), where the per-unit-cover rate of increase

138 (hereafter recovery rate) among tabulate Acropora reefs $(1.48[1.36,1.88])$ was $30 \%$ to $41 \%$

139 higher than on soft-coral dominated reefs $(1.05[0.97,1.30])$, mixed coral assemblage reefs $(1.08$

$140 \quad[0.97,1.43])$, and Poritidae/Alcyoniidae reefs $(1.13$ [1.01, 1.44]) in periods with no acute

141 disturbance (Fig 2a). This combined high intrinsic rate of increase and low density dependence

142 (Fig 2d) underlies the rapid recovery observed among Acropora-dominated reefs throughout the

143 Indo-Pacific ${ }^{15,49,50}$. Most striking however, was clear evidence of the strong, negative impact that

144 exposure to high nutrient and/or the high turbidity conditions associated with riverine plume

145 waters has on coral recovery rates across the GBR (Fig 2g), having a far greater influence than 
146 protection from fishing, likely due, in part, to the relatively low levels of fishing pressure among 147 most GBR reefs ${ }^{51}$.

148

149 To understand the historical impact deleterious conditions associated with high sediment and

150 nutrient loads associated with riverine plume waters has had on hard coral recovery, we

151 estimated maximum potential reductions in PFc that could be achieved given a theoretical return

152 to pre-European conditions (a 65\% reduction in PFc), using the average estimated proportions of

153 anthropogenic contributions for dissolved inorganic nitrogen (DIN) and fine sediments from

154 across the $\mathrm{GBR}^{52}$ (Extended Data Methods). Given these theoretical levels, we find that chronic

155 river-influenced plumes from anthropogenic influenced riverine loads have reduced recovery

156 rates among inshore Mixed and Poritidae/Alcyoniidae reefs and mid-shelf reefs by -12\% [-14\%, -

157 10\%] to -27\% [-31\%, -21\%] (Supplemental Information). Given that the riverine plume metric

158 (PFc) represents the frequency of plume waters over a 14 year period during wet season

159 conditions (Nov to April), the modelling of a reduction in PFc, represents one of the first broad-

160 scale estimate of the impact coastal agriculture and development has had on coral recovery on the

161 GBR. These negative effects are likely due to factors such as light attenuation from resuspension

162 of fine sediment imported to the GBR via flood plumes causing reductions in coral growth ${ }^{40,53,54}$

163 and symbiont photosynthesis ${ }^{55}$, as well as from higher competition with algae that benefit from

164 nutrient enrichment ${ }^{19}$ limiting coral recruitment ${ }^{56}$. 
166 Given that water quality is the strongest management-related predictor of both reef resistance and

167 recovery, we assessed what reduction of riverine-plume frequency (measured as PFc) would be necessary to counteract expected increases in thermal stress relative to 1995-2017 conditions. We

169 simulated future hard coral dynamics out to 2050 from our model given projected increases in 170 thermal stress and bleaching potential under RCP $4.5^{13}$, now considered the most likely scenario 171 for future climate ${ }^{57}$, as well as GBR-specific trends ${ }^{58}$ and the most recent empirical rates of 172 observed thermal stress and bleaching ${ }^{2}$ (Fig 3a). We find that, unless corals are able to rapidly 173 adapt to warming conditions, $11 \%$ to $23 \%$ improvements in the frequency of elevated sediments 174 and/or high wet-season nutrient plumes waters will be necessary to counteract future thermal 175 stress expected by 2050 among inshore and mid-shelf reefs, which are exposed to the greatest 176 PFc levels (Fig 3b,d). While plumes themselves are not anthropogenic, high PFc values do 177 represent high frequency of brown or green waters that predominate in anthropogenic conditions. 178 These large-scale water quality improvements are within the scope of proposed targets for 179 sediment and nutrient loads under the State of Queensland's Draft Reef 2050 Water Quality 180 Improvement Plan 2017-2022 ${ }^{59}$. However, given that the targets are not likely to be met (SCS 181 2017) and even with the positive effects of reduced probabilities of CoTS outbreaks accounted 182 for in our model, current water-quality management is unlikely to buffer projected thermal stress 183 among more intact Acropora-dominated reefs, due to the low exposure of offshore waters to land 184 runoff and to resuspended sediment (Extended Data Fig 6). Given current trends ${ }^{2,58}$, we find that 185 more than 65\% reductions in $\mathrm{PF}_{\mathrm{C}}$ would be needed to counteract predicted bleaching rates to 1862050 among offshore Acropora reefs, levels that exceed the change since pre-European 
conditions, making such an improvement likely impossible. The prospects for corals are much better if they are able to adaptively respond to recent thermal stress through natural or assisted evolution $^{60}$. Under 80 -year rolling climatology adaptation conditions ${ }^{13}$, only modest $(<5 \%) \mathrm{PF}_{\mathrm{C}}$ improvements would be expected to close the predicted bleaching gap in all but the Acroporadominated reefs (Fig 3c).

Our results help to clarify the role catchment management actions could play in promoting reef resilience where high nutrients, high productivity and high turbidity changes in the inshore reefs dominates over fishing as the most pervasive driver of reef dynamics. Specifically, we find evidence that closed areas and herbivory have less influence than particular aspects of water quality (i.e turbidity) on coral recovery rates across the GBR (Fig 2g). In locations where fishing pressure is greater than the GBR, herbivory and protected areas can have a greater role in resilience-based management of reefs ${ }^{6}$. Even on the GBR, protected areas have been shown to increase resistance to disturbance, helping retain overall community structure ${ }^{61}$ that will become increasingly important as climate stress increases. Our results do highlight the need to understand the influence of water quality, particularly the differences between fine sediments and high nutrients conditions on coral reef resilience more broadly, especially as it is one of the most poorly quantified and understood stressors on reefs. It is likely that improvements in different aspects of water quality is a more common driver of reef resilience in other locations, as shown in some case studies ${ }^{62,63}$. 
208 While local actions to mitigate climate-change impacts are unlikely to keep up with escalating 209 threats from climate change itself ${ }^{64}$, concurrent actions are needed to support coral reef resilience 210 through the medium term if reefs are to have the largest opportunity to recover ${ }^{65-67}$. Recent back211 to-back bleaching events across two thirds of the GBR underscore the need to act quickly and 212 implement management measures that mitigate the multiple pressures facing the $\mathrm{GBR}^{8}$. Our 213 results also show how mitigation of the inputs of high sediment and nutrient loads to improve 214 water quality plume conditions along the Queensland coast will give the GBR the best possible 215 chance to maintain some level of resilience in an increasingly disturbed future.

\section{References}

219 1. Hughes, T. P. et al. Global warming transforms coral reef assemblages. Nature 556, 492 (2018).

$220 \quad 2 . \quad$ Hughes, T. P. et al. Spatial and temporal patterns of mass bleaching of corals in the Anthropocene. Science 221 (80-. ). 359, 80-83 (2018).

$222 \quad$ 3. Zaneveld, J. R. et al. Overfishing and nutrient pollution interact with temperature to disrupt coral reefs down 223 to microbial scales. Nat. Commun. 7, 11833 (2016).

224 4. Hughes, T. P. et al. Phase shifts, herbivory and the resilience of coral reefs to climate change. Curr. Biol. 17, $225 \quad 360-365$ (2007).

226 5. McClanahan, T. R. et al. Prioritizing key resilience indicators to support coral reef management in a 227 changing climate. PLoS One 7, e42884 (2012).

228 6. Graham, N. A. J. et al. Managing resilience to reverse phase shifts in coral reefs. Front. Ecol. Environ. 11, $229 \quad 1-2(2013)$.

$230 \quad 7 . \quad$ Vercelloni, J., Caley, M. J. \& Mengersen, K. Crown-of-thorns starfish undermine the resilience of coral 
231 populations on the Great Barrier Reef. Glob. Ecol. Biogeogr. 26, 846-853 (2017).

232 8. Hughes, T. P. et al. Global warming and recurrent mass bleaching of corals. Nature 543, 373-377 (2017).

233 9. De’ath, G., Fabricius, K. E., Sweatman, H. \& Puotinen, M. The 27--year decline of coral cover on the Great Barrier Reef and its causes. Proc. Natl. Acad. Sci. 109, 17995-17999 (2012).

10. Cheal, A. J., MacNeil, M. A., Emslie, M. J. \& Sweatman, H. The threat to coral reefs from more intense cyclones under climate change. Glob. Chang. Biol. 23, 1511-1524 (2017).

11. Maynard, J. et al. Projections of climate conditions that increase coral disease susceptibility and pathogen abundance and virulence. Nat. Clim. Chang. 5, 688-694 (2015).

12. Frieler, K. et al. Limiting global warming to $2 \mathrm{C}$ is unlikely to save most coral reefs. Nat. Clim. Chang. 3, 165-170 (2013).

13. Logan, C. A., Dunne, J. P., Eakin, C. M. \& Donner, S. D. Incorporating adaptive responses into future projections of coral bleaching. Glob. Chang. Biol. 20, 125-139 (2014).

14. Ainsworth, T. D. et al. Climate change disables coral bleaching protection on the Great Barrier Reef. Science (80-. ). 352, 338-342 (2016).

15. Gilmour, J. P., Smith, L. D., Heyward, A. J., Baird, A. H. \& Pratchett, M. S. Recovery of an isolated coral reef system following severe disturbance. Science (80-. ). 340, 69-71 (2013).

16. Bellwood, D. R., Hughes, T. P. \& Hoey, A. S. Sleeping functional group drives coral-reef recovery. Curr. Biol. 16, 2434-2439 (2006).

17. Done, T. J. Phase shifts in coral reef communities and their ecological significance. Hydrobiologia 247, 121132 (1992).

18. Johns, K. A., Osborne, K. O. \& Logan, M. Contrasting rates of coral recovery and reassembly in coral communities on the Great Barrier Reef. Coral Reefs 33, 553-563 (2014).

19. Fabricius, K., De’ath, G., McCook, L., Turak, E. \& Williams, D. M. Changes in algal, coral and fish assemblages along water quality gradients on the inshore Great Barrier Reef. Mar. Pollut. Bull. 51, 384-398 (2005). 

(2010).

259 21. Thompson, A., Schroeder, T., Brando, V. E. \& Schaffelke, B. Coral community responses to declining water quality: whitsunday Islands, Great Barrier Reef, Australia. Coral Reefs 33, 923-938 (2014).

22. Ortiz, J.-C. et al. Impaired recovery of the Great Barrier Reef under cumulative stress. Sci. Adv. 4, eaar6127 (2018).

23. Ateweberhan, M., McClanahan, T. R., Graham, N. A. J. \& Sheppard, C. R. C. Episodic heterogeneous decline and recovery of coral cover in the Indian Ocean. Coral Reefs 30, 739-752 (2011).

24. Hughes, T. P. et al. Coral reefs in the Anthropocene. Nature 546, 82-90 (2017).

25. Hughes, T. P., Day, J. C. \& Brodie, J. Securing the future of the Great Barrier Reef. Nature Climate Change 5, 508-511 (2015).

26. Smith, J., Smith, C. \& Hunter, C. An experimental analysis of the effects of herbivory and nutrient enrichment on benthic community dynamics on a Hawaiian reef. Coral Reefs 19, 332-342 (2001).

27. Fabricius, K. E., Okaji, K. \& De’ath, G. Three lines of evidence to link outbreaks of the crown-of-thorns

28. Willis, B. L., Page, C. A. \& Dinsdale, E. A. Coral disease on the Great Barrier Reef. Coral Heal. Dis. 69104 (2004). doi:10.1007/978-3-662-06414-6

29. Ferrier-Pagès, C., Gattuso, J.-P., Dallot, S. \& Jaubert, J. Effect of nutrient enrichment on growth and photosynthesis of the zooxanthellate coral Stylophora pistillata. Coral Reefs 19, 103-113 (2000).

30. Houk, P., Musburger, C. \& Wiles, P. Water quality and herbivory interactively drive coral-reef recovery patterns in American Samoa. PLoS One 5, e13913 (2010).

31. Brodie, J. E. et al. Setting ecologically relevant targets for river pollutant loads to meet marine water quality requirements for the Great Barrier Reef, Australia: A preliminary methodology and analysis. Ocean Coast. Manag. 143, 136-147 (2017). 
283 33. Nyström, M., Graham, N. A. J., Lokrantz, J. \& Norström, A. V. Capturing the cornerstones of coral reef 284 resilience: linking theory to practice. Coral Reefs 27, 795-809 (2008).

285 34. Sweatman, H., Delean, S. \& Syms, C. Assessing loss of coral cover on Australia’s Great Barrier Reef over 286 two decades, with implications for longer-term trends. Coral reefs 30, 521-531 (2011).

287 35. Pratchett, M. S., Caballes C.F., Rivera-Posada J.A. \& Sweatman, H. P. A. Limits to understanding and 288 managing outbreaks of crown-of-thorns starfish ( Acanthaster spp.). Oceanogr. Mar. Biol. Annu. Rev. 52, 133-200 (2014).

36. Emslie, M. J., Cheal, A. J., Sweatman, H. P. A. \& Delean, S. Recovery form disturbance of coral reef fish

37. Emslie, M. J., Pratchett, M. S., Cheal, A. J. \& Osborne, K. Great Barrier Reef butterflyfish community structure: the role of shelf position and benthic community type. Coral Reefs 29, 705-715 (2010).

38. GBRMPA. Great Barrier Reef Marine Park zoning plan 2003. 1-211 (Great Barrier Reef Marine Park Authority, 2004).

39. Petus, C., da Silva, E. T., Devlin, M., Wenger, A. S. \& Álvarez-Romero, J. G. Using MODIS data for mapping of water types within river plumes inthe Great Barrier Reef, Australia: Towards the production of river plume risk maps for reef and seagrass ecosystems. J. Environ. Manage. 137, 163-177 (2014).

40. Fabricius, K. E., Logan, M. M., Weeks, S. J., Lewis, S. E. \& Brodie, J. Changes in water clarity in response to river discharges on the Great Barrier Reef continental shelf: 2002-2013. Esturarine, Coast. Shelf Sci. 173,

41. Brodie, J., Devlin, M. \& Lewis, S. Potential Enhanced Survivorship of Crown of Thorns Starfish Larvae due to Near-Annual Nutrient Enrichment during Secondary Outbreaks on the Central Mid-Shelf of the Great Barrier Reef, Australia. Diversity 9, 17 (2017).

42. Vega Thurber, R. L. et al. Chronic nutrient enrichment increases prevalence and severity of coral disease and bleaching. Glob. Chang. Biol. 20, 544-554 (2014). 
44. Clark, T. R. et al. U-Th dating reveals regional-scale decline of branching Acropora corals on the Great Barrier Reef over the past century. Proc. Natl. Acad. Sci. 114, 10350-10355 (2017).

45. Mongin, M. et al. The exposure of the Great Barrier Reef to ocean acidification. Nat. Commun. 7, (2016).

46. Safaie, A. et al. High frequency temperature variability reduces the risk of coral bleaching. Nat. Commun. 9, 1671 (2018).

47. Wiedenmann, J. et al. Nutrient enrichment can increase the susceptibility of reef corals to bleaching. Nat. Clim. Chang. 3, 160-164 (2013).

48. Wooldridge, S. A. \& Brodie, J. E. Environmental triggers for primary outbreaks of crown-of-thorns starfish on the Great Barrier Reef, Australia. Mar. Pollut. Bull. 101, 805-815 (2015).

49. Connell, J. H., Hughes, T. P. \& Wallace, C. C. A 30-year study of coral abundance, recruitment, and disturbance at several scales in space and time. Ecol. Monogr. 67, 461-488 (1997).

50. Kayanne, H., Harii, S., Ide, Y. \& Akimoto, F. Recovery of coral populations after the 1998 bleaching on Shiraho Reef, in the southern Ryukyus, NW Pacific. Mar. Ecol. Prog. Ser. 239, 93-103 (2002).

51. MacNeil, M. A. et al. Recovery potential of the world’s coral reef fishes. Nature 520, 341-344 (2015).

52. Brodie, J. et al. Development of basin-specific ecologically relevant water quality targets for the Great Barrier Reef. (2017). doi:10.13140/RG.2.2.36754.35526

53. Anthony, K. R. N. \& Fabricius, K. E. Shifting roles of heterotrophy and autotrophy in coral energetics under varying turbidity. J. Exp. Mar. Bio. Ecol. 252, 221-253 (2000).

54. Petus, C. et al. Estimating the exposure of coral reefs and seagrass meadows to land-sourced contaminants in river flood plumes of the great barrier reef: Validating a simple satellite risk framework with environmental data. Remote Sens. 8, 1-30 (2016).

55. Bessell-Browne, P. et al. Impacts of turbidity on corals: The relative importance of light limitation and suspended sediments. Mar. Pollut. Bull. 117, 161-170 (2017).

56. Birrell, C. L., McCook, L. J. \& Willis, B. L. Effects of algal turfs and sediment on coral settlement. in Marine Pollution Bulletin 51, 408-414 (2005).

57. Change, I. P. on C. Climate change 2014: Mitigation of climate change. 3, (Cambridge University Press, 
2015).

336 58. Van Hooidonk, R. et al. Local-scale projections of coral reef futures and implications of the Paris

337 Agreement. Sci. Rep. 6, 39666 (2016).

338 59. The State of Queensland. Draft Reef 2050 Water Quality Improvement Plan 2017-2022 for public

339 consultation. (2017).

340 60. van Oppen, M. J. H. et al. Shifting paradigms in restoration of the world's coral reefs. Glob. Chang. Biol. 23, $341 \quad 3437-3448(2017)$.

342 61. Mellin, C., Aaron MacNeil, M., Cheal, A. J., Emslie, M. J. \& Julian Caley, M. Marine protected areas 343 increase resilience among coral reef communities. Ecol. Lett. 19, 629-637 (2016).

344 62. Smith, S. V, Kimmerer, W. J., Laws, E. A., Brock, R. E. \& Walsh, T. W. Kaneohe Bay sewage diversion 345 experiment: perspectives on ecosystem responses to nutritional perturbation. Pacific Sci. 35, 279-395 (1981).

346 63. Graham, N. A. J., Jennings, S., MacNeil, M. A., Mouillot, D. \& Wilson, S. K. Predicting climate-driven regime shifts versus rebound potential in coral reefs. Nature 518, 94-97 (2015).

348 64. Norström, A. V et al. Guiding coral reef futures in the Anthropocene. Front. Ecol. Environ. 14, 490-498 (2016).

65. Hoegh-Guldberg, O., Poloczanska, E. S., Skirving, W. \& Dove, S. Coral Reef Ecosystems under Climate Change and Ocean Acidification. Front. Mar. Sci. 4, 158 (2017).

66. Wolff, N. H., Mumby, P. J., Devlin, M. \& Anthony, K. R. N. Vulnerability of the Great Barrier Reef to climate change and local pressures. Glob. Chang. Biol. 23, 3437-3448 (2018).

67. Anthony, K. et al. New interventions are needed to save coral reefs. Nat. Ecol. Evol. 1, 1420 (2017). counts of juvenile corals. Long-term monitoring of the Great Barrier Reef standard operational procedure number 10. Aust. Inst. Mar. Sci. (2008). 
361

362

363

364

365

366

367

368

369

370

371

372

373

374

375

376

377

378

379

380

381

382

383

384 385

71. Osborne, K., Dolman, A. M., Burgess, S. C. \& Johns, K. A. Disturbance and the dynamics of coral cover on the Great Barrier Reef (1995--2009). PLoS One 6, e17516 (2011).

72. Bass, D. K. \& Miller, I. R. Crown-of-thorns starfish and coral surveys using the manta tow and scuba search techniques. SOP 1 (1996).

73. Puotinen, M., Maynard, J. A., Beeden, R., Radford, B. \& Williams, G. J. A robust operational model for predicting where tropical cyclone waves damage coral reefs. Sci. Rep. 6, 1-12 (2016).

74. Stockwell, B., Jadloc, C. R. L., Abesamis, R. A., Alcala, A. C. \& Russ, G. R. Trophic and benthic responses to no-take marine reserve protection in the Philippines. Mar. Ecol. Prog. Ser. 389, 1-15 (2009).

75. Cheal, A. J. et al. Coral--macroalgal phase shifts or reef resilience: links with diversity and functional roles of herbivorous fishes on the Great Barrier Reef. Coral reefs 29, 1005-1015 (2010).

76. McCook, L. J. et al. Adaptive management of the Great Barrier Reef: A globally significant demonstration of the benefits of networks of marine reserves. Proc. Natl. Acad. Sci. 107, 18278-18285 (2010).

77. Baith, K., Lindsay, R., Fu, G. \& McClain, C. R. SeaDAS, a data analysis system for ocean-color satellite sensors. Eos, Trans. Am. Geophys. Union 82, 202-202 (2001).

78. Alvarez-Romero, J. G. et al. A novel approach to model exposure of coastal-marine ecosystems to riverine flood plumes based on remote sensing techniques. J. Environ. Manage. 119, 194-207 (2013).

79. Devlin, M. J. et al. Mapping the pollutants in surface riverine flood plume waters in the Great Barrier Reef, Australia. Mar. Pollut. Bull. 65, 224-235 (2012).

80. Devlin, M. \& Schaffelke, B. Spatial extent of riverine flood plumes and exposure of marine ecosystems in the Tully coastal region, Great Barrier Reef. Mar. Freshw. Res. 60, 1109-1122 (2009).

81. Osborne, K. et al. Delayed coral recovery in a warming ocean. Glob. Chang. Biol. 23, 3869-3881 (2017).

82. Salvatier, J., Wiecki, T. V \& Fonnesbeck, C. Probabilistic programming in Python using PyMC3. PeerJ Comput. Sci. 2, e55 (2016).

83. Brooks, S. P., Catchpole, E. A. \& Morgan, B. J. T. Bayesian animal survival estimation. Stat. Sci. 15, 357376 (2000).

84. McCulloch, M. et al. Coral record of increased sediment flux to the inner Great Barrier Reef since European 
settlement. Nature 421, 727-730 (2003).

85. Waterhouse, J. et al. The risk from anthropogenic pollutants to Great Barrier Reef coastal and marine ecosystems. in Scientific Consensus Statement 2017: A synthesis of the science of land-based water quality impacts on the Great Barrier Reef (State of Queensland, 2017).

86. Csaszar, N. B. M., Ralph, P. J., Frankham, R., Berkelmans, R. \& van Oppen, M. J. H. Estimating the potential for adaptation of corals to climate warming. PLoS One 5, e9751 (2010).

393

394

Supplementary Information is available in the online version of the paper.

395

396

397

398

399

400

401

402

403

404

405

406

407

405

Acknowledgements This research was supported by an NSERC Canada Research Chair awarded to A MacNeil, Australian Research Council Discovery Early Career Researcher Awards to C Mellin (DE140100701) and (DE160100741) to C Drovandi, and a Royal Society University Research Fellowship awarded to N Graham (UF140691). We thank the exceptional staff at the Australian Institute of Marine Science for their support and critical discussions of the work. Data and coding used in this paper are available through the GitHub links in the Methods. Many thanks to H Sweatman, B Schaffelke, K Fabricius, A Thompson, K Anthony, and three anonymous reviewers for constructive comments on the manuscript. Special thanks to R van Hooidonk at NOAA for graciously and quickly providing GBR-specific DHW predictions.

Author Contributions M.A.M conceived of the study with N.A.J.G.; M.A.M., C.M., N.H.W., M.D. and S.M. collected or collated the data; M.A.M, C.M., C.D., and K.M. developed and implemented the analyses with ideas from T.R.M., S.M., and N.H.W.; M.A.M., C.M., and 
408 N.A.J.G. wrote the paper, and all authors contributed significantly to the interpretation and 409 editing of the manuscript.

410

411 Author Information Reprints and permissions information is available at

412 www.nature.com/reprints. The authors declare no competing financial interests. Correspondence 413 and request for materials should be addressed to M.A.M. (a.macneil@dal.ca).

414

415 

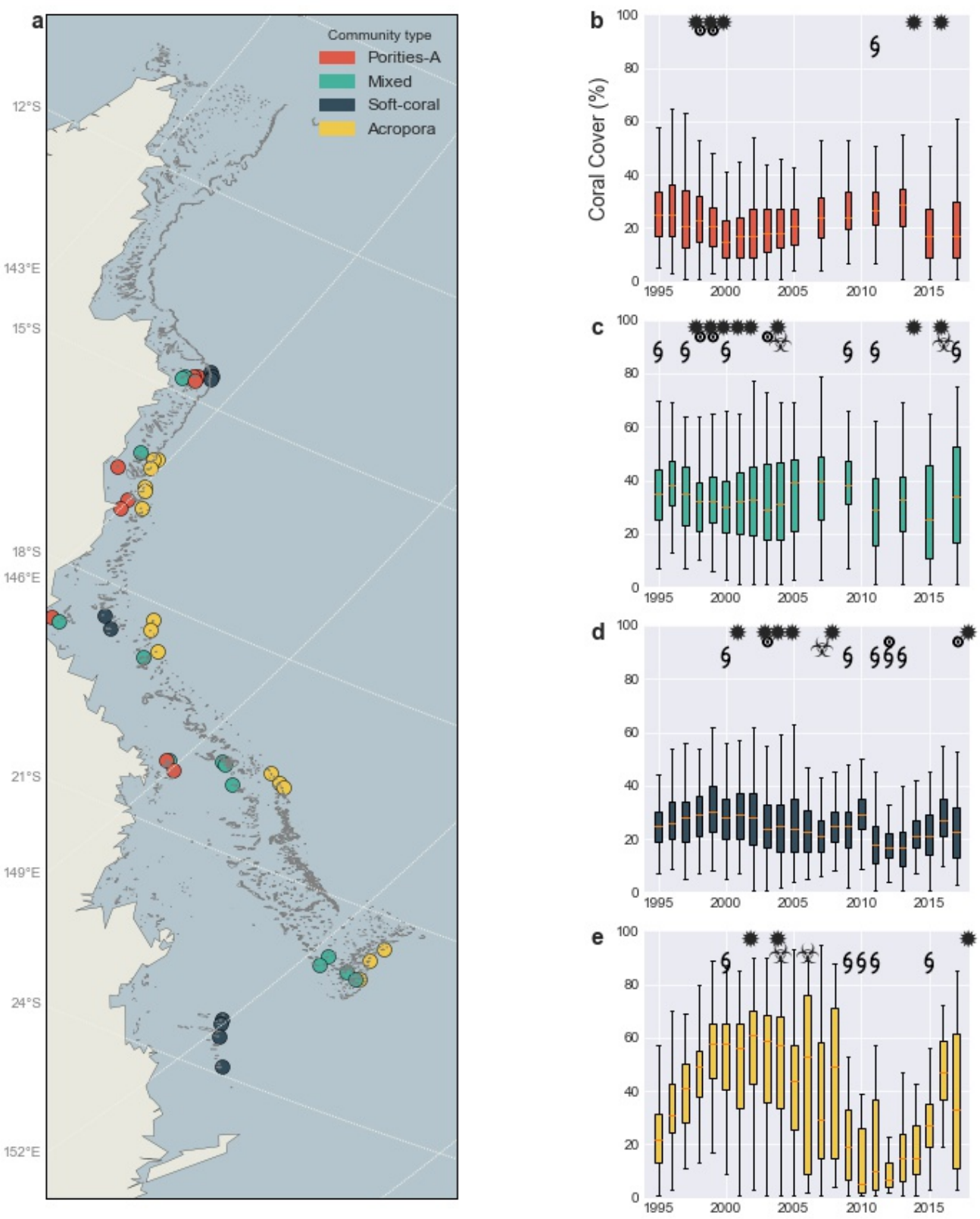

417 Figure 1 | Study locations and trends in hard coral cover across the Great Barrier Reef. a) Survey locations for AIMS long-term monitoring program (LTMP) reefs $(n=46), 1995-2017(n=12,523$ individual transects), grouped by community type from Emslie et al. 2010. Trends in hard coral cover, with symbols indicating occasions when these community types were exposed to major disturbances, such as storms (§), bleaching events ( , disease outbreaks ( coral dominated, and e) Acropora-dominated community types. Boxplots show center line (median), box limits (upper and lower quartiles) whiskers (1.5x interquartile range). 

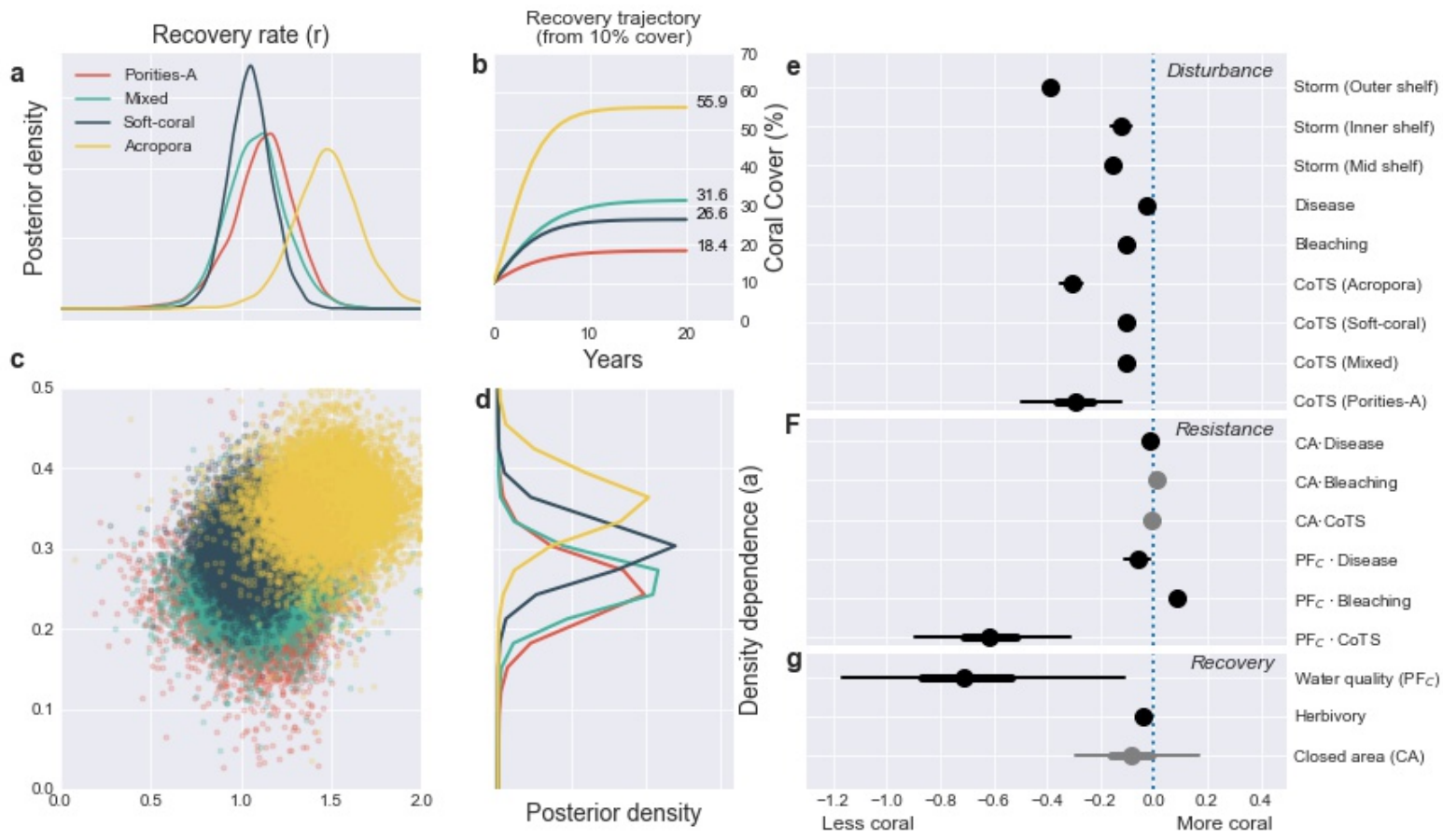

Figure 2 | Bayesian posterior model results for hierarchical model of hard coral decline and recovery across the Great Barrier Reef. Data from AIMS long-term monitoring program (LTMP) reefs ( $\mathrm{n}=46)$, 1995-2017 $(\mathrm{n}=12,523$ individual transects). a) Posterior distribution of intrinsic rate of increase $(r)$ among GBR coral community types; b) median predicted recovery trajectories from $10 \%$ initial cover for GBR coral community types, given average conditions and an absence of coral loss from disturbance; c) scatterplot of joint posterior samples for model $r$ (intrinsic rate of increase) and $a$ (density dependence) Gompertz-based coral model parameters; d) posterior distribution of $a$ among GBR coral community types; and e) posterior effect size plot for Gompertz-based coral model covariate parameters, including posterior medians (circle), 50\% uncertainty intervals (thick line), and 95\% uncertainty intervals (thin line), with grey dots indicating parameters where the $95 \%$ UI overlaps zero, and black dots where they do not. CA $\cdot \mathrm{xxx}$ and $\mathrm{PFC} \cdot \mathrm{xxx}$ indicate interactions in the model. Full model posteriors are presented in Extended Data Figs 2 and 3. 

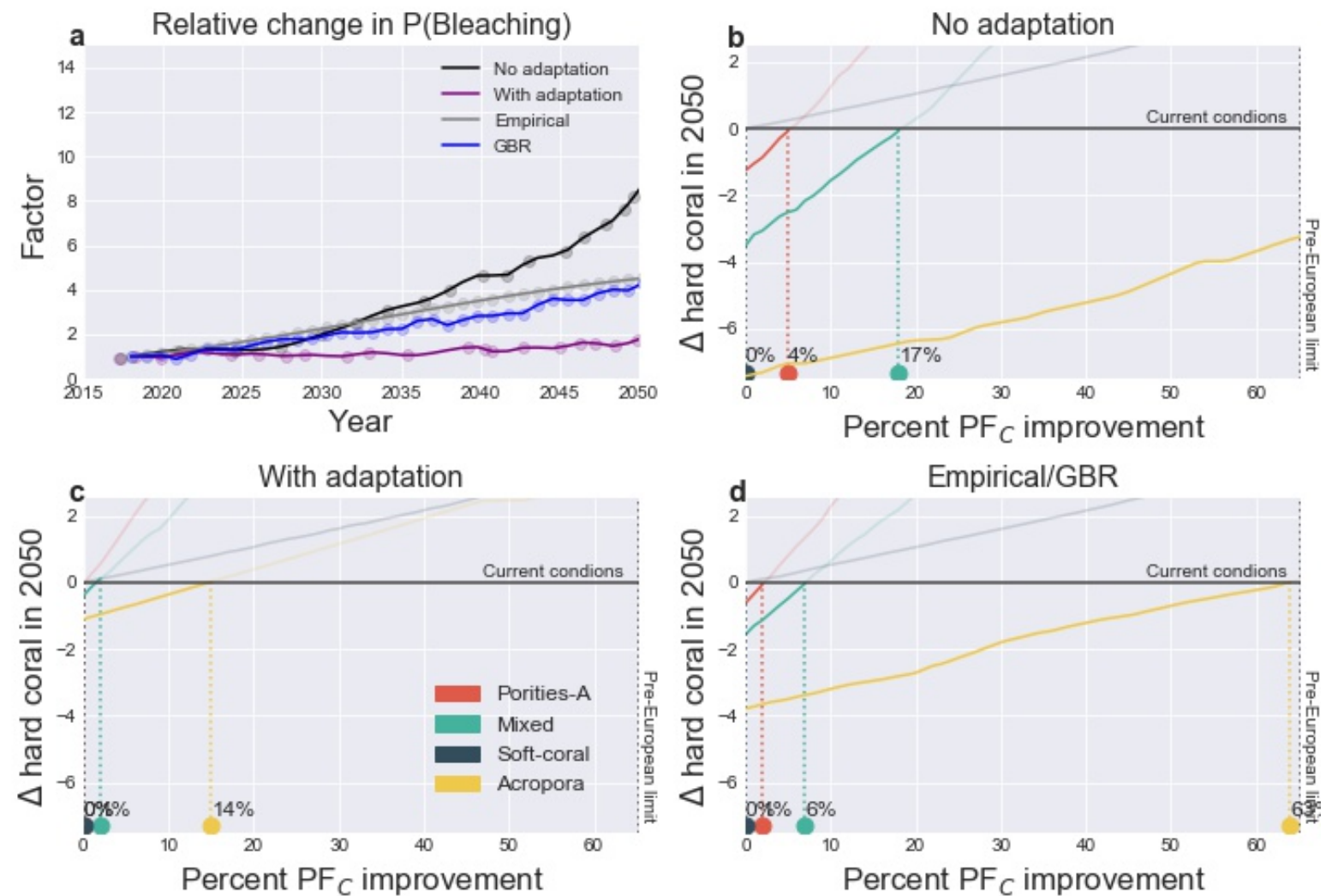

Figure 3 | Projected effects of changes in the average frequency of river-influenced plumes across the Great

Barrier Reef. a) Increases in relative bleaching potential under RCP 4.5 given no adaptation, with a rolling 80 year window of adaptation ${ }^{13}$, expected GBR-specific trend from van Hooidonk et al. 2016, and the empirical trend estimated from Hughes et al. 2018. Projected net percent differences in median hard coral cover $(\Delta)$ relative to longterm expected coral cover under current disturbance conditions (i.e. no increase in frequency of bleaching-derived coral loss) given improvements in average river influenced plumes $\left(\mathrm{PF}_{\mathrm{C}}\right)$ given $\mathrm{b}$ ) no adaptation, $\mathrm{c}$ ) with adaptation, and d) average trends from two published estimates ${ }^{2,58}$. Points along the $\mathrm{x}$-axis indicate level of $\mathrm{PF}_{\mathrm{C}}$ improvement necessary to counteract projected coral loss due to increases in the frequency of destructive bleaching in panel A. Pre-European limits (dotted line on far right) derived from estimates of proportion of anthropogenic influence. 
454 METHODS

\section{Survey data}

456

457 The data underlying our analysis come from the Australian Institute of Marine Science (AIMS)

458 Long Term Monitoring Program (LTMP) ${ }^{68}$ which includes 46 reefs that were monitored annually

459 between 1993 and 2005, and biennially thereafter. Our data includes surveys from 1995 to 2017

460 (conducted October to April each year), with multiple bleaching and other disturbance events.

461 Note that the most severe bleaching events of 2016/2017 occurred north of most survey locations,

462 where no long-term monitoring exists and our data and model do not include samples from the

463 northernmost sector or the heavily-impacted Keppels region. Surveyed reefs were primarily in the

464 central and southern GBR, the areas where routine monitoring occurs (Figure 1a). Importantly for

465 this study, each of the 46 survey reefs includes 15 fixed-position $50 \mathrm{~m}$ transects, a survey design

466 ideally suited to studying inter-annual dynamics. Within each survey reef, five transects were

467 spaced $<50 \mathrm{~m}$ apart at each of three sites along the 6-9m contour of the reef slope. For each

468 transect in each observed year, the percentage of hard coral cover was estimated by the

469 percentage of 200 randomly selected individual points, five at a time, from each of 40 still images

470 of the benthos and identifying to the genus level ${ }^{69}$. 
474 Because quantifying reef dynamics requires long-term monitoring data that includes a range of 475 disturbance events and subsequent periods of recovery, these northernmost locations currently 476 provide little information as to rates of recovery. They will do so however over the coming 477 decades where - bar an additional severe bleaching event - their recovery will provide a test of 478 our estimated recovery rates absent human influence. Therefore, from our model we predict there 479 is a greater than $50 \%$ chance that Acropora-dominated reefs within the northernmost sector of the 480 GBR will reach 60\% [38\%, 91\%] average coral cover within 10 years (from 10\% median coral 481 cover $^{1}$ ). These predictions are into areas north of our study area and constitute an important test 482 of the applicability of our approach among reefs outside our survey data.

483

\section{Use of the term 'resilience'}

485

486 Our definition of resilience specifically refers to the factors that moderate the impact of acute 487 disturbances (resistance) and the rate at which corals increase after experiencing them (recovery). 488 While we recognise a more nuanced, alternative definition of resilience as being "the capacity of 489 a system to absorb disturbance and reorganize while undergoing change so as to still retain 490 essentially the same function, structure, identity, and feedbacks” ${ }^{70}$, our study does not compare 491 structure and function of coral reefs explicitly. Rather our goal was to quantify hard coral cover 492 dynamics through time, and to understand the various processes that influence them. In this, our 493 formulation is clear and fit for purpose. 


\section{Model covariates}

496

To make inferences regarding potential factors influencing coral decline and recovery, we collected covariates purported to impact these processes, including levels of herbivory, water quality, fisheries restriction, coral community type, and disturbance history. While some covariates were unambiguous (such as zoning), for most processes we selected the best-available

501 covariates that captured their key features. At the scale of our analysis, this process necessarily 502 averages over factors not represented within these covariates, which is common in statistical

503 modelling but also makes our results conditional on the assumptions made in using these

504 covariates and the structure of our model. It is important to note that we standardized each model 505 covariate so as to be broadly comparable within resilience and recovery model sub-components.

506 This means that when we state 'given average environmental conditions' about a given effect size 507 for a covariate, it assumes the other covariates are at their standardized average (0), which will 508 often not occur in practice. This formulation allows us to most readily compare among groups 509 and assess the relative importance of model covariates. Sub-headings include abbreviations used 510 in the model equations below.

514 For each transect in each observed year, the percentage of hard coral cover was estimated by 515 randomly selecting 200 individual points, five at a time, from each of 40 still images of the 
516 benthos ${ }^{69}$. Our communities followed Emslie et al. $2010^{37}$, who used a principal components 517 analysis (PCA) of average proportions of identified coral families to allocate each of the survey 518 reefs to one of four coral community types, including Acropora, Poritidae/Alcyoniidae, mixed519 coral, and soft-coral dominated reef types (Figure S1). These community types formed the basis 520 of hierarchical community groupings for subsequent modelling, where individual reefs were 521 nested within specific community types.

Disturbance history - COT, STO, BLE, DIS, UNK

525 While conducting LTMP surveys, AIMS staff recorded instances where $>5 \%$ of total hard coral 526 cover was lost between surveys, assigning attribution to the loss based on five potential 527 disturbances: crown-of-thorns starfish outbreaks (COTS); storms or cyclones (STO); coral 528 bleaching (BLE); coral disease (DIS); or, where the cause of coral loss was not identified, 529 unknown (UNK). Each disturbance was identified by distinctive and identifiable effects on 530 corals, such as the presence of CoTS individuals or feeding scars, or dislodged and broken coral 531 indicative of cyclone damage ${ }^{71}$. Each of these disturbances was originally coded for presence (1) 532 or absence (0) per transect per year, which we matched to existing quantitative estimates of 533 disturbance severity for subsequent modelling. Specifically, percent coral cover bleached was 534 interpolated using inverse distance weighting (maximum distance $=1^{\circ}$; minimum observations $=$ 535 3) from extensive aerial surveys for the three mass bleaching events on the GBR (1998, 2002, 536 and 2016/2017). Interpolated maps of CoTS densities were generated by inverse distance 
537 weighting (maximum distance $=1^{\circ}$; minimum observations $=3$ ) from the manta tow data

538 collected by the Australian Institute of Marine Science in every year between 1996 and $2017^{72}$.

539 The potential for cyclone damage was estimated based on 4-km resolution reconstructed sea state

540 as per Puotinen et al. $2016{ }^{73}$. This model predicts the incidence of seas rough enough to severely

541 damage corals (top one-third of wave heights $>4 \mathrm{~m}$ ) caused by cyclones for every cyclone

542 between 1996-2017. CoTS and bleaching are sometimes thought of as ecosystem responses to

543 disturbances from nutrients and thermal stress ${ }^{35}$. Note we did not plot UNK effects in the text

544 because these represent losses of corals that didn't have attribution in the data, but are likely from

545 one of the other recorded categories and therefore constitute observation error.

546

547 Herbivory - HRB

548

549 To represent the potential influence of herbivorous fish on the disturbance and recovery dynamics

550 of coral reefs ${ }^{74}$ we included a measure of the total abundance of herbivorous reef fishes present

551 in each survey year. As part of the LTMP, AIMS staff have also collected concurrent reef fish

552 data, using standardized belt transect methods ${ }^{68}$. For each of the LTMP transects, divers

553 conducted underwater visual surveys (UVC) whereby they estimated the abundance of

554 herbivorous fishes (including scrapers, excavators, grazer/detritivores, and algal browsers) ${ }^{75}$

555 present within $2.5 \mathrm{~m}$ either side of a $50 \mathrm{~m}$ tape measure used to demarcate the survey area.

556

557 Zoning - MPA 
559 To account for potential impacts of fishing on the disturbance and recovery dynamics of the 560 LTMP survey reefs, we included a dummy variable to indicate if fishing was present (0) or not

561 (1). Thirty-five percent of reefs within the GBR have been protected as no-fishing or no-entry 562 zones since at least 2004, including many within the LTMP (Table S1); we included both no563 fishing and no-entry areas in our MPA covariate. It is worth noting that there is some evidence of 564 poaching affecting ecosystem function among no-fishing reefs on the GBR ${ }^{76}$.

Water quality exposure $-P F_{C}$

567

568 In the GBR region, the use of MODIS true colour imagery has provided a spatially rich technique 569 in the estimation of river plume extent and improved the assessment of the level of exposure of 570 inshore coral reefs and seagrass meadows to river plumes. River plume mapping utilising true 571 colour imagery has been applied as a method of characterising the water quality conditions 572 associated with periods of elevated river flow through the wet season. Various products have 573 been produced using different methods of extraction, aggregation through annual and multi574 annual time frames, and integration to provide robust information on annual wet season 575 conditions and to report decadal time frames around water quality during wet season conditions.

576 While PFc represents an assessment of reduced water quality conditions in the wet season, future 577 work should consider the complexity of the year round turbidity issues associated with the 578 resuspension of the finer sediment during high wind conditions ${ }^{31,40}$ 
580 River plume maps are produced using MODIS Level-0 data acquired from the NASA Ocean

581 Colour website (http://oceancolor.gsfc.nasa.gov) and converted into true-colour images with a 582 spatial resolution of $500 \mathrm{~m} \times 500 \mathrm{~m}$ using SeaDAS ${ }^{77}$. The true colour images were then 583 spectrally enhanced from Red-Green-Blue to Hue-Saturation-Intensity colour systems and 584 classified to six distinct river plumes water types defined by their colour (RGB/HSI signatures) 585 properties and hereafter referred to as plume colour classes ${ }^{39,78}$. Three types of plume waters 586 were distinguished following previously described methods ${ }^{79,80}$ as: Primary, characterized by 587 high turbidity and nutrients; secondary, characterized by high chlorophyll; and tertiary, 588 characterized by high color dissolved organic material (CDOM). The clustering of the colour 589 classes into six groups characterising the water types in the river plumes is through supervised 590 classification using spectral signatures from the changes in colour associated with the gradient of 591 river plumes. Each of the defined six colour classes (CC1-CC6) is characterised by different 592 concentrations of optically active components (TSS, CDOM, and chlorophyll-a) that influence 593 the light attenuation and can vary the impact on the underlying ecological systems. CC1-CC3 594 correspond to the brownish turbid water masses with high sediment and CDOM concentrations,

595 CC4 and CC5 to the greener water masses with lower sediment concentrations favouring 596 increased coastal productivity, and CC6 is the transitional water mass between plume waters and 597 marine waters ${ }^{39,54}$. These categorizations were used to underpin our composite index, PFC which 598 represents the frequency of all plume water types (i.e CC1 - CC6). Thus, the PFc is a metric that 
represents a range of water quality conditions, high turbidity, high CDOM and increased

600 productivity.

601

602 Frequency of riverine plume exposure for each reef was measured using the MODIS satellite

603 observations from 2000 - 2014. Data represent the proportion of wet season weeks, defined as

604 the period from November to April $(\mathrm{N}=22$ weeks per year) in which plumes, corresponding to

605 the defined colour classes (CC1 - CC6) were present. To avoid backscattering interference

606 leading to false plume characterization at or near reef margins, plume data were processed as

607 follows ${ }^{66}$ : Firstly, the Great Barrier Reef Marine Park Authority reef polygon layer, with a $1 \mathrm{~km}$

608 buffer applied, was used to eliminate any plume data pixels it intersected. Secondly, the

609 remaining valid pixels were used to interpolate plume data across the data gaps (reef locations)

610 resulting from the first step. The resulting clean layer was used here to assess reef exposure to

611 the plume frequency $(\mathrm{PFC})$.

612

\section{Coral dynamics model}

614

615 Our lack of overall change in coral cover estimates differed from previously-reported losses of

616 total cover on the GBR - which were from $28 \%$ to $22 \%{ }^{34}$ and from $28.0 \%$ to $13.8 \%{ }^{9}$ - reflecting

617 methodological, spatial, and temporal differences among datasets and the problems inherent in

618 using linear trends to describe long-term, density-dependent dynamics. To overcome these issues,

619 we employed a Gompertz-based modelling approach to estimate recovery rates independent of 
the magnitude of prior coral loss, using a hierarchical structure that included four characteristic

621 community types: Acropora, Poritidae/Alcyoniidae, mixed-coral, and soft-coral dominated reefs

62237 . Our model includes two growth components: an intrinsic growth rate and a term for density

623 dependence that controls for slower growth rate at near carrying capacity. As the resilience of

624 coral reefs rests on a combination of their ability to resist disturbances and to recover from them,

625 our models included explicit representations of both processes. Our modelling approach is

626 unusual in explicitly representing both decline and recovery using what have traditionally been

627 population models for abundance, rather than simple linear trends. Our development of these

628 models was based on the innovation of Fukaya et al. 2010 32 , who reconciled Gompertz-based

629 population models with coverage-limited sessile organisms. A similar approach has been used

630 previously by Osborne et al. $2017^{81}$, based on our initial development of these methods for this

631 analysis. To model resistance to disturbance, we include explanatory variables relating to levels

632 of fishing protection and herbivory, as well as the interactions between disturbance types and

633 both our index of the frequency of riverine plume waters ( $\left.\mathrm{PF}_{\mathrm{C}}\right)$ and closed areas (CA). Post-

634 disturbance recovery rates were modeled using variables relating to water quality exposure $\left(\mathrm{PF}_{\mathrm{C}}\right)$,

635 herbivory, and protection from fishing (CA).

636 To quantify the coral disturbance and recovery dynamics of LTMP reefs between 1995 and 2017,

637 we developed a coverage-based Bayesian hierarchical statistical model based on the work of

638 Fukaya et al. $2010^{32}$. This Gompertz-based model quantifies the intrinsic growth rate $(r)$ and

639 strength of density dependence (a) for sessile species, expressed as coverage of a defined

640 sampling area. In our case this was the number of visual points $(y)$ out of 100 that contained hard 
641 coral within the LTMP data per transect. Using a Binomial (BIN) observation model, we 642 assumed a hierarchy where transect level observations (i) at time $(t)$, were nested within reef $(r)$, 643 nested within each community type $(c)$ :

644

645

$$
y_{c r t, i} \sim B I N\left(100, p_{c r t, i}\right)
$$

646

647

with mean model

648

650

651

$$
\begin{aligned}
\log \left(p_{c r t, i} \times 100\right) & =\left(r_{c r}+\gamma_{7} H_{E R B_{t, i}}\right)+\left(1-a_{c r}\right) \log \left(y_{c r t-1, i}\right)+\gamma_{2, c} C O T_{t, i}+\gamma_{3, c} S T O_{t, i}+\gamma_{4, c} B L E_{t, i}+\gamma_{5, c} D I S_{t, i} \\
& +\gamma_{6, c} U N K_{t, i}+\gamma_{8} B L E \times P F_{C, r}+\gamma_{9} C O T \times P F_{C, r}+\gamma_{10} D I S \times P F_{C, r}+\gamma_{11} U N K \times P F_{C, r}+\gamma_{12} B L E \\
& \times C A_{r}+\gamma_{13} C O T \times C A_{r}+\gamma_{14} D I S \times C A_{r}+\gamma_{15} U N K \times C A_{r}
\end{aligned}
$$

652

653 and where

654

$$
a_{c r} \sim N\left(a_{c}, \sigma_{a c}\right)
$$

655

656

657

658

$$
\begin{gathered}
r_{c r} \sim N\left(r_{c}+k_{0} C A_{r}+k_{1} P F_{T}, \sigma_{r c}\right) \\
a_{c}, r_{c}, k_{0}, k_{1}, \gamma_{1 \ldots 15} \sim N(0,100) \\
\sigma_{a c}, \sigma_{r c} \sim U(0,100)
\end{gathered}
$$

659

660 Note that in this formulation, each coral community type had their own global mean at the top

661 level of the hierarchy. These models were run in a Bayesian framework, using the PyMC3

662 package in Python $^{82}$, with inferences made from 5000 samples of the No U-Turn Sampler

663 (NUTS) algorithm. Parallel chains were run, from starting values initialized automatically by an 
664 Automatic Differentiation Variational Inference (ADVI) algorithm, to look for convergence of 665 posterior parameter estimates using the Gelman-Rubin convergence statistic (R-hat); posterior 666 traces and predictive intervals, as well as Bayesian p-values ${ }^{83}$ were examined for evidence of 667 convergence and model fit. All model diagnostics showed efficient exploration of the posterior 668 and provided no evidence for lack of model fit (Extended Data Figs S2, S3, S4).

669

670

\section{Disturbance probabilities}

671

672 To quantify the disturbance history within the LTMP data from 1995 to 2017, we elected to 673 model the average annual disturbance using a simple Bayesian hierarchical Bernoulli model 674 (BNI) for each coral community type and disturbance (DIS):

675

676

677

678

679

680

681

682 683 yielding a community-type specific disturbance probability ( $\left.p_{d c}\right)$ for each disturbance type $(d)$, where DIS is one of COT, STO, BLE, DIS, or UNK. Probabilities from this model were then multiplied by median disturbance severity when used in our future projections. 
To evaluate the effect of increased sediment plumes on recovery rates and the capacity to

687 compensate for increased bleaching events, we initially relied on paleo-ecological estimates from

688 McCullugh et al. $2003^{84}$, who used coral cores from the central GBR to estimate modern and pre-

689 European barium loads at $4.8+0.6 \times 10^{12}$ and $3.5+0.2 \times 10^{12} \mathrm{~L} /$ wk respectively (a $66 \%$ difference).

690 However, based on the comments of a knowledgeable reviewer, we revised this threshold to

691 better reflect contemporary understanding of anthropogenic nutrient and sediment loads.

692 Specifically we used the average proportion of DIN and fine sediment loads attributed to

693 anthropogenic sources among the Wet Tropics, Burdekin, Mackay/Whitsunday, Fitzroy, and

694 Burnett Mary NRM regions in Tables 10 \& 11 of Brodie et al. $2017^{52}$ to estimate an overall

695 potential PFC improvement of 65\% (See Figures and summary statistics code below for exact

696 calculations). Note however that our PFc composite index has only recently been developed over

697 the entire GBR; the next step in this work is to calculate PFc at an individual catchment level to

698 allow specific management actions across the GBR, in line with both the scientific consensus

699 statement ${ }^{85}$ and the target water quality ${ }^{52}$ reports.

700

$701 \quad$ Future projections

702

703 Current conditions scenario

704

705 To estimate how future changes in overall water quality would influence the disturbance and 706 recovery dynamics of LTMP reefs, we simulated a range of improved water quality scenarios 
from 2018 to 2050 by proportionally reducing each of $\mathrm{PF}_{\mathrm{C}}$ values by $1 \%$ increments (up to a $66 \%$

708 reduction), while sampling from the posterior distributions of model [1] and the disturbance

709 probabilities from [2]. These simulations were run 9999 times per $\mathrm{PF}_{\mathrm{T}}$ value, initiated using the

710 observed 2015 hard coral cover values.

711

712

Bleaching scenarios

713

714 The frequency of coral bleaching events is widely predicted to increase steadily over coming

715 years ${ }^{2}$, putting coral reefs in great danger of repeated bleaching events from which they have

716 insufficient time to recover. To simulate realistic scenarios for increased bleaching frequency, we

717 used modelled data from the 80 year rolling climatology scenario in Figure S1 of Logan et al.

$7182014^{13}$ to develop a bleaching factor relative to 2017. Specifically, we scaled the predictions in

719 that figure by the value in 2017, giving us a ratio of predicted bleaching probability per year out

720 to 2050 (Figure 3A) that we used to re-scale the probability of bleaching per year, relative to the

721 posteriors in model [2]. We then simulated from the posteriors of models [1] and [2], as for the

722 current conditions scenario above, but multiplying the annual bleaching probability by the new

723 bleaching factor ratios. In keeping with the results of Logan et al. ${ }^{13}$, this process included both a

724 no-adaptation scenario, where the bleaching probability remains constant as temperatures

725 increase, and a rolling-window of adaptation, whereby corals are able to adapt to an 80-year

726 window of change in the underlying climate ${ }^{86}$. We also included a GBR-specific estimate of

727 relative projected bleaching probability, using the predicted increase in degree heating months 
728 (DHM) under RCP 4.5 from van Hooidonk et al ${ }^{58}$. Finally, given the dramatic, large-scale

729 bleaching events on the GBR in 2016, we downloaded the data from Hughes et al. $2018^{2}$ and

730 used the same linear modelling approach they did, but in a Bayesian framework, to estimate the

731 projected trend in severe bleaching recurrence through to 2050 (See supplemental code; Extended

732 Data Fig 5). Because this probability of severe bleaching exceeds that of actual mortality, we re-

733 scaled the projected trend represented by the blue line in Extended Data Figure 5 relative to its

734 value in 2017, giving an additional bleaching factor ratio based on their empirical results. As

735 above, this bleaching factor ratio was multiplied by our estimated probability of bleaching

736 mortality in simulating future bleaching events.

737

738

739 Code and data to reproduce the entire analysis is available on GitHub:

740 Bayesian hierarchical model:

741 https://gist.github.com/mamacneil/fb907d588e13c0a359fbad11359cceac

742

743 Annual disturbance probabilities:

744 https://gist.github.com/mamacneil/3b35088bbcc0da0957ccf89c7ba11956

745

746 Empirical model from Hughes et al. 2018:

747 https://gist.github.com/mamacneil/245bb4c009c0c2637772dc6fa23e37cd 
749 Plots from Hughes et al. 2018 analysis:

750 https://gist.github.com/mamacneil/967430a86a195587d9dc2e97d1a91c1f

751

752 Future disturbance simulations:

753 https://gist.github.com/mamacneil/06f814247816c0b1254045284435b695

754

755 Figures and summary statistics:

756 https://gist.github.com/mamacneil/bcb49741174174960a6ecd9c93bb56eb

757

758 Data:

759 All code and be posted to an open GitHub repository upon publication.

760

761 Additional references

762 1. Hughes, T. P. et al. Global warming transforms coral reef assemblages. Nature 556, 492 763 (2018).

764 2. Hughes, T. P. et al. Spatial and temporal patterns of mass bleaching of corals in the $765 \quad$ Anthropocene. Science (80-. ). 359, 80-83 (2018).

766 3. Zaneveld, J. R. et al. Overfishing and nutrient pollution interact with temperature to 767 disrupt coral reefs down to microbial scales. Nat. Commun. 7, 11833 (2016).

768 4. Hughes, T. P. et al. Phase shifts, herbivory and the resilience of coral reefs to climate 769 change. Curr. Biol. 17, 360-365 (2007). 
770 5. McClanahan, T. R. et al. Prioritizing key resilience indicators to support coral reef 771 management in a changing climate. PLoS One 7, e42884 (2012).

772 6. Graham, N. A. J. et al. Managing resilience to reverse phase shifts in coral reefs. Front. 773 Ecol. Environ. 11, 1-2 (2013).

774 7. Vercelloni, J., Caley, M. J. \& Mengersen, K. Crown-of-thorns starfish undermine the 775 resilience of coral populations on the Great Barrier Reef. Glob. Ecol. Biogeogr. 26, 846776853 (2017).

777 8. Hughes, T. P. et al. Global warming and recurrent mass bleaching of corals. Nature 543, 778 779

10. Cheal, A. J., MacNeil, M. A., Emslie, M. J. \& Sweatman, H. The threat to coral reefs from more intense cyclones under climate change. Glob. Chang. Biol. 23, 1511-1524 (2017).

11. Maynard, J. et al. Projections of climate conditions that increase coral disease

12. Frieler, K. et al. Limiting global warming to $2 \mathrm{C}$ is unlikely to save most coral reefs. Nat. susceptibility and pathogen abundance and virulence. Nat. Clim. Chang. 5, 688-694 Clim. Chang. 3, 165-170 (2013).

13. Logan, C. A., Dunne, J. P., Eakin, C. M. \& Donner, S. D. Incorporating adaptive responses into future projections of coral bleaching. Glob. Chang. Biol. 20, 125-139 (2014). 
14. Ainsworth, T. D. et al. Climate change disables coral bleaching protection on the Great Barrier Reef. Science (80-. ). 352, 338-342 (2016).

15. Gilmour, J. P., Smith, L. D., Heyward, A. J., Baird, A. H. \& Pratchett, M. S. Recovery of an isolated coral reef system following severe disturbance. Science (80-. ). 340, 69-71 (2013).

16. Bellwood, D. R., Hughes, T. P. \& Hoey, A. S. Sleeping functional group drives coral-reef recovery. Curr. Biol. 16, 2434-2439 (2006).

17. Done, T. J. Phase shifts in coral reef communities and their ecological significance. Hydrobiologia 247, 121-132 (1992).

18. Johns, K. A., Osborne, K. O. \& Logan, M. Contrasting rates of coral recovery and reassembly in coral communities on the Great Barrier Reef. Coral Reefs 33, 553-563 (2014).

19. Fabricius, K., De’ath, G., McCook, L., Turak, E. \& Williams, D. M. Changes in algal, coral and fish assemblages along water quality gradients on the inshore Great Barrier Reef. Mar. Pollut. Bull. 51, 384-398 (2005).

20. Uthicke, S., Thompson, A. \& Schaffelke, B. Effectiveness of benthic foraminiferal and coral assemblages as water quality indicators on inshore reefs of the Great Barrier Reef, Australia. Coral Reefs 29, 209-225 (2010).

21. Thompson, A., Schroeder, T., Brando, V. E. \& Schaffelke, B. Coral community responses to declining water quality: whitsunday Islands, Great Barrier Reef, Australia. Coral Reefs 33, 923-938 (2014). 
812 22. Ortiz, J.-C. et al. Impaired recovery of the Great Barrier Reef under cumulative stress. Sci. Adv. 4, eaar6127 (2018).

814 23. Ateweberhan, M., McClanahan, T. R., Graham, N. A. J. \& Sheppard, C. R. C. Episodic heterogeneous decline and recovery of coral cover in the Indian Ocean. Coral Reefs 30, 739-752 (2011).

24. Hughes, T. P. et al. Coral reefs in the Anthropocene. Nature 546, 82-90 (2017).

25. Hughes, T. P., Day, J. C. \& Brodie, J. Securing the future of the Great Barrier Reef. Nature Climate Change 5, 508-511 (2015).

26. Smith, J., Smith, C. \& Hunter, C. An experimental analysis of the effects of herbivory and nutrient enrichment on benthic community dynamics on a Hawaiian reef. Coral Reefs 19, 332-342 (2001).

27. Fabricius, K. E., Okaji, K. \& De'ath, G. Three lines of evidence to link outbreaks of the crown-of-thorns seastar Acanthaster planci to the release of larval food limitation. Coral Reefs 29, 593-605 (2010).

28. Willis, B. L., Page, C. A. \& Dinsdale, E. A. Coral disease on the Great Barrier Reef. Coral Heal. Dis. 69-104 (2004). doi:10.1007/978-3-662-06414-6

29. Ferrier-Pagès, C., Gattuso, J.-P., Dallot, S. \& Jaubert, J. Effect of nutrient enrichment on growth and photosynthesis of the zooxanthellate coral Stylophora pistillata. Coral Reefs 19, 103-113 (2000).

30. Houk, P., Musburger, C. \& Wiles, P. Water quality and herbivory interactively drive coralreef recovery patterns in American Samoa. PLoS One 5, e13913 (2010). 
833

834

835

836

837

838

839

840

841

842

843

844

845

846

847

848

849

850

851

852

853

31. Brodie, J. E. et al. Setting ecologically relevant targets for river pollutant loads to meet marine water quality requirements for the Great Barrier Reef, Australia: A preliminary methodology and analysis. Ocean Coast. Manag. 143, 136-147 (2017).

32. Fukaya, K., Okuda, T., Nakaoka, M., Hori, M. \& Noda, T. Seasonality in the strength and spatial scale of processes determining intertidal barnacle population growth. J. Anim. Ecol. 79, 1270-1279 (2010).

33. Nyström, M., Graham, N. A. J., Lokrantz, J. \& Norström, A. V. Capturing the cornerstones of coral reef resilience: linking theory to practice. Coral Reefs 27, 795-809 (2008).

34. Sweatman, H., Delean, S. \& Syms, C. Assessing loss of coral cover on Australia’s Great Barrier Reef over two decades, with implications for longer-term trends. Coral reefs 30, 521-531 (2011).

35. Pratchett, M. S., Caballes C.F., Rivera-Posada J.A. \& Sweatman, H. P. A. Limits to understanding and managing outbreaks of crown-of-thorns starfish ( Acanthaster spp.). Oceanogr. Mar. Biol. Annu. Rev. 52, 133-200 (2014).

36. Emslie, M. J., Cheal, A. J., Sweatman, H. P. A. \& Delean, S. Recovery form disturbance of coral reef fish communities on the \{Great Barrier Reef, Australia\}. Mar. Ecol. Ser. 371, 177-190 (2008).

37. Emslie, M. J., Pratchett, M. S., Cheal, A. J. \& Osborne, K. Great Barrier Reef butterflyfish community structure: the role of shelf position and benthic community type. Coral Reefs 29, 705-715 (2010). 
854

855

856

857

858

859

860

861

862

863

864

865

866

867

868

869

870

871

872

873

874

38. GBRMPA. Great Barrier Reef Marine Park zoning plan 2003. 1-211 (Great Barrier Reef Marine Park Authority, 2004).

39. Petus, C., da Silva, E. T., Devlin, M., Wenger, A. S. \& Álvarez-Romero, J. G. Using MODIS data for mapping of water types within river plumes inthe Great Barrier Reef, Australia: Towards the production of river plume risk maps for reef and seagrass ecosystems. J. Environ. Manage. 137, 163-177 (2014).

40. Fabricius, K. E., Logan, M. M., Weeks, S. J., Lewis, S. E. \& Brodie, J. Changes in water clarity in response to river discharges on the Great Barrier Reef continental shelf: 20022013. Esturarine, Coast. Shelf Sci. 173, A1-A15 (2016).

41. Brodie, J., Devlin, M. \& Lewis, S. Potential Enhanced Survivorship of Crown of Thorns Starfish Larvae due to Near-Annual Nutrient Enrichment during Secondary Outbreaks on the Central Mid-Shelf of the Great Barrier Reef, Australia. Diversity 9, 17 (2017).

42. Vega Thurber, R. L. et al. Chronic nutrient enrichment increases prevalence and severity of coral disease and bleaching. Glob. Chang. Biol. 20, 544-554 (2014).

43. van Woesik, R., Cacciapaglia, C. \& Randall, C. J. Thermal-Stress Response of Coral Communities to Climate Change. in The Cnidaria, Past, Present and Future 545-552 (Springer, 2016).

44. Clark, T. R. et al. U-Th dating reveals regional-scale decline of branching Acropora corals on the Great Barrier Reef over the past century. Proc. Natl. Acad. Sci. 114, 10350-10355 (2017).

45. Mongin, M. et al. The exposure of the Great Barrier Reef to ocean acidification. Nat. 
Commun. 7, (2016).

46. Safaie, A. et al. High frequency temperature variability reduces the risk of coral bleaching. Nat. Commun. 9, 1671 (2018).

47. Wiedenmann, J. et al. Nutrient enrichment can increase the susceptibility of reef corals to bleaching. Nat. Clim. Chang. 3, 160-164 (2013).

48. Wooldridge, S. A. \& Brodie, J. E. Environmental triggers for primary outbreaks of crownof-thorns starfish on the Great Barrier Reef, Australia. Mar. Pollut. Bull. 101, 805-815 (2015).

49. Connell, J. H., Hughes, T. P. \& Wallace, C. C. A 30-year study of coral abundance, recruitment, and disturbance at several scales in space and time. Ecol. Monogr. 67, 461488 (1997).

50. Kayanne, H., Harii, S., Ide, Y. \& Akimoto, F. Recovery of coral populations after the 1998 bleaching on Shiraho Reef, in the southern Ryukyus, NW Pacific. Mar. Ecol. Prog. Ser. 239, 93-103 (2002).

51. MacNeil, M. A. et al. Recovery potential of the world's coral reef fishes. Nature 520, 341344 (2015).

52. Brodie, J. et al. Development of basin-specific ecologically relevant water quality targets for the Great Barrier Reef. (2017). doi:10.13140/RG.2.2.36754.35526

53. Anthony, K. R. N. \& Fabricius, K. E. Shifting roles of heterotrophy and autotrophy in coral energetics under varying turbidity. J. Exp. Mar. Bio. Ecol. 252, 221-253 (2000).

54. Petus, C. et al. Estimating the exposure of coral reefs and seagrass meadows to land- 
sourced contaminants in river flood plumes of the great barrier reef: Validating a simple satellite risk framework with environmental data. Remote Sens. 8, 1-30 (2016).

898 55. Bessell-Browne, P. et al. Impacts of turbidity on corals: The relative importance of light limitation and suspended sediments. Mar. Pollut. Bull. 117, 161-170 (2017).

900

56. Birrell, C. L., McCook, L. J. \& Willis, B. L. Effects of algal turfs and sediment on coral settlement. in Marine Pollution Bulletin 51, 408-414 (2005).

57. Change, I. P. on C. Climate change 2014: Mitigation of climate change. 3, (Cambridge University Press, 2015).

58. Van Hooidonk, R. et al. Local-scale projections of coral reef futures and implications of the Paris Agreement. Sci. Rep. 6, 39666 (2016).

59. The State of Queensland. Draft Reef 2050 Water Quality Improvement Plan 2017-2022 for public consultation. (2017).

60. van Oppen, M. J. H. et al. Shifting paradigms in restoration of the world's coral reefs. Glob. Chang. Biol. 23, 3437-3448 (2017).

61. Mellin, C., Aaron MacNeil, M., Cheal, A. J., Emslie, M. J. \& Julian Caley, M. Marine protected areas increase resilience among coral reef communities. Ecol. Lett. 19, 629-637 (2016).

62. Smith, S. V, Kimmerer, W. J., Laws, E. A., Brock, R. E. \& Walsh, T. W. Kaneohe Bay sewage diversion experiment: perspectives on ecosystem responses to nutritional perturbation. Pacific Sci. 35, 279-395 (1981).

63. Graham, N. A. J., Jennings, S., MacNeil, M. A., Mouillot, D. \& Wilson, S. K. Predicting 
climate-driven regime shifts versus rebound potential in coral reefs. Nature 518, 94-97

918 (2015).

919

64. Norström, A. V et al. Guiding coral reef futures in the Anthropocene. Front. Ecol. Environ. 14, 490-498 (2016).

65. Hoegh-Guldberg, O., Poloczanska, E. S., Skirving, W. \& Dove, S. Coral Reef Ecosystems under Climate Change and Ocean Acidification. Front. Mar. Sci. 4, 158 (2017).

66. Wolff, N. H., Mumby, P. J., Devlin, M. \& Anthony, K. R. N. Vulnerability of the Great Barrier Reef to climate change and local pressures. Glob. Chang. Biol. 23, 3437-3448 (2018).

67. Anthony, K. et al. New interventions are needed to save coral reefs. Nat. Ecol. Evol. 1, 1420 (2017).

68. Sweatman, H. P. A. et al. Long-term monitoring of the Great Barrier Reef. Aust. Inst. Mar. Sci. (2008).

69. Jonker, M., Johns, K. \& Osborne, K. Surveys of benthic reef communities using digital photography and counts of juvenile corals. Long-term monitoring of the Great Barrier Reef standard operational procedure number 10. Aust. Inst. Mar. Sci. (2008).

70. Walker, B., Holling, C. S., Carpenter, S. R. \& Kinzig, A. Resilience, Adaptability and Transformability in Social - ecological Systems. Ecol. Soc. 9, 5 (2004).

71. Osborne, K., Dolman, A. M., Burgess, S. C. \& Johns, K. A. Disturbance and the dynamics of coral cover on the Great Barrier Reef (1995--2009). PLoS One 6, e17516 (2011). 
tow and scuba search techniques. SOP 1 (1996).

939 73. Puotinen, M., Maynard, J. A., Beeden, R., Radford, B. \& Williams, G. J. A robust operational model for predicting where tropical cyclone waves damage coral reefs. Sci. Rep. 6, 1-12 (2016).

74. Stockwell, B., Jadloc, C. R. L., Abesamis, R. A., Alcala, A. C. \& Russ, G. R. Trophic and benthic responses to no-take marine reserve protection in the Philippines. Mar. Ecol. Prog. Ser. 389, 1-15 (2009).

75. Cheal, A. J. et al. Coral--macroalgal phase shifts or reef resilience: links with diversity and functional roles of herbivorous fishes on the Great Barrier Reef. Coral reefs 29, 10051015 (2010).

76. McCook, L. J. et al. Adaptive management of the Great Barrier Reef: A globally significant demonstration of the benefits of networks of marine reserves. Proc. Natl. Acad. Sci. 107, 18278-18285 (2010).

951 77. Baith, K., Lindsay, R., Fu, G. \& McClain, C. R. SeaDAS, a data analysis system for 952 ocean-color satellite sensors. Eos, Trans. Am. Geophys. Union 82, 202-202 (2001).

78. Alvarez-Romero, J. G. et al. A novel approach to model exposure of coastal-marine ecosystems to riverine flood plumes based on remote sensing techniques. J. Environ. Manage. 119, 194-207 (2013).

79. Devlin, M. J. et al. Mapping the pollutants in surface riverine flood plume waters in the Great Barrier Reef, Australia. Mar. Pollut. Bull. 65, 224-235 (2012). 
marine ecosystems in the Tully coastal region, Great Barrier Reef. Mar. Freshw. Res. 60, 1109-1122 (2009).

961 81. Osborne, K. et al. Delayed coral recovery in a warming ocean. Glob. Chang. Biol. 23, 3869-3881 (2017).

963

964

965

966

967

968

969

970

971

972

973

974

975

976

977
82. Salvatier, J., Wiecki, T. V \& Fonnesbeck, C. Probabilistic programming in Python using PyMC3. PeerJ Comput. Sci. 2, e55 (2016).

83. Brooks, S. P., Catchpole, E. A. \& Morgan, B. J. T. Bayesian animal survival estimation. Stat. Sci. 15, 357-376 (2000).

84. McCulloch, M. et al. Coral record of increased sediment flux to the inner Great Barrier Reef since European settlement. Nature 421, 727-730 (2003).

85. Waterhouse, J. et al. The risk from anthropogenic pollutants to Great Barrier Reef coastal and marine ecosystems. in Scientific Consensus Statement 2017: A synthesis of the science of land-based water quality impacts on the Great Barrier Reef (State of Queensland, 2017).

86. Csaszar, N. B. M., Ralph, P. J., Frankham, R., Berkelmans, R. \& van Oppen, M. J. H. Estimating the potential for adaptation of corals to climate warming. PLoS One 5, e9751 (2010). 


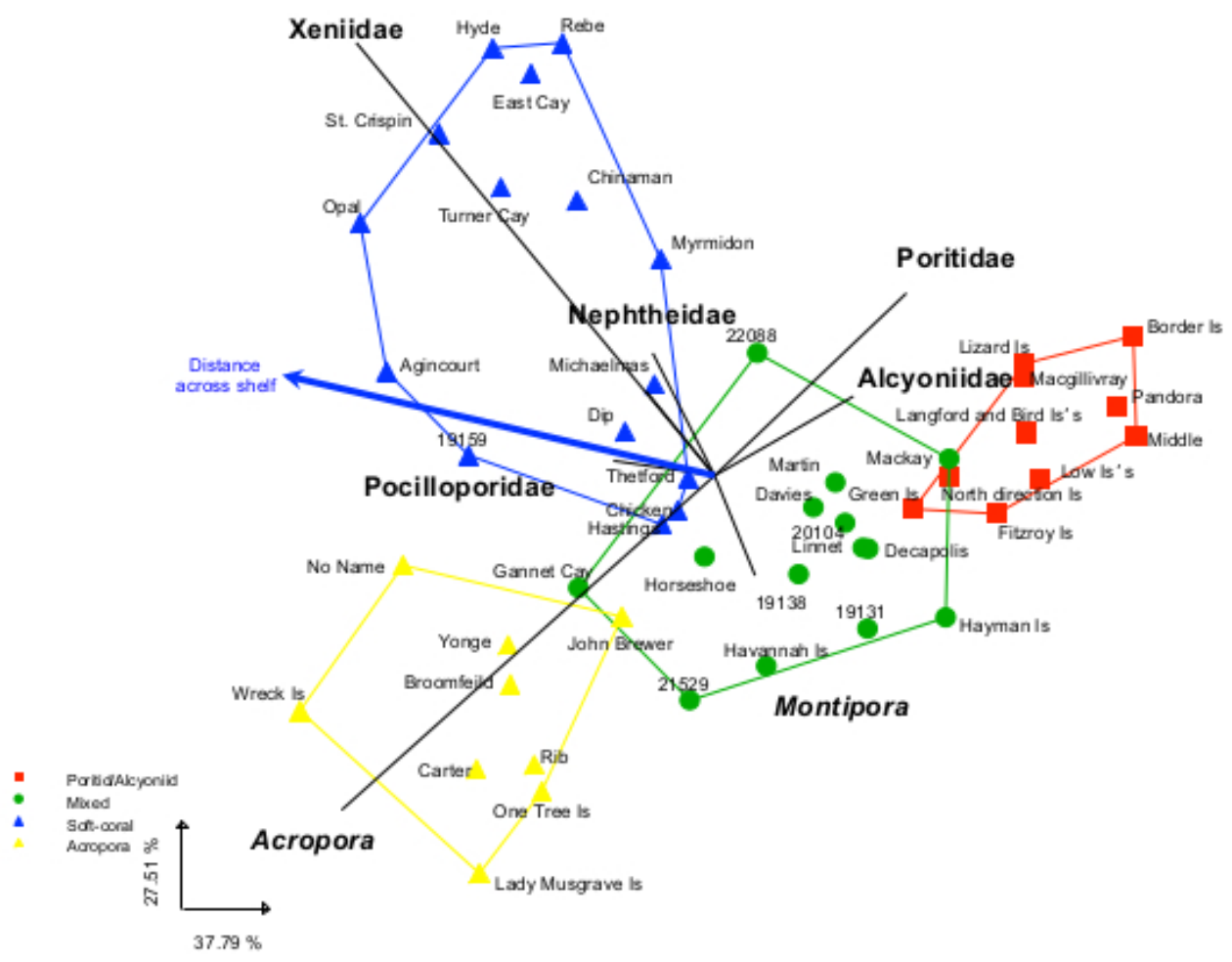

979 Extended Data Figure 1 | Principal component analysis clustering of benthic community composition across 980 the Great Barrier Reef. Underlying data are from 690 transects surveyed annually on 46 reefs within the Australian Institute of Marine Science Long Term Monitoring Program 1995-2017. After Emslie et al. 2010 37. 

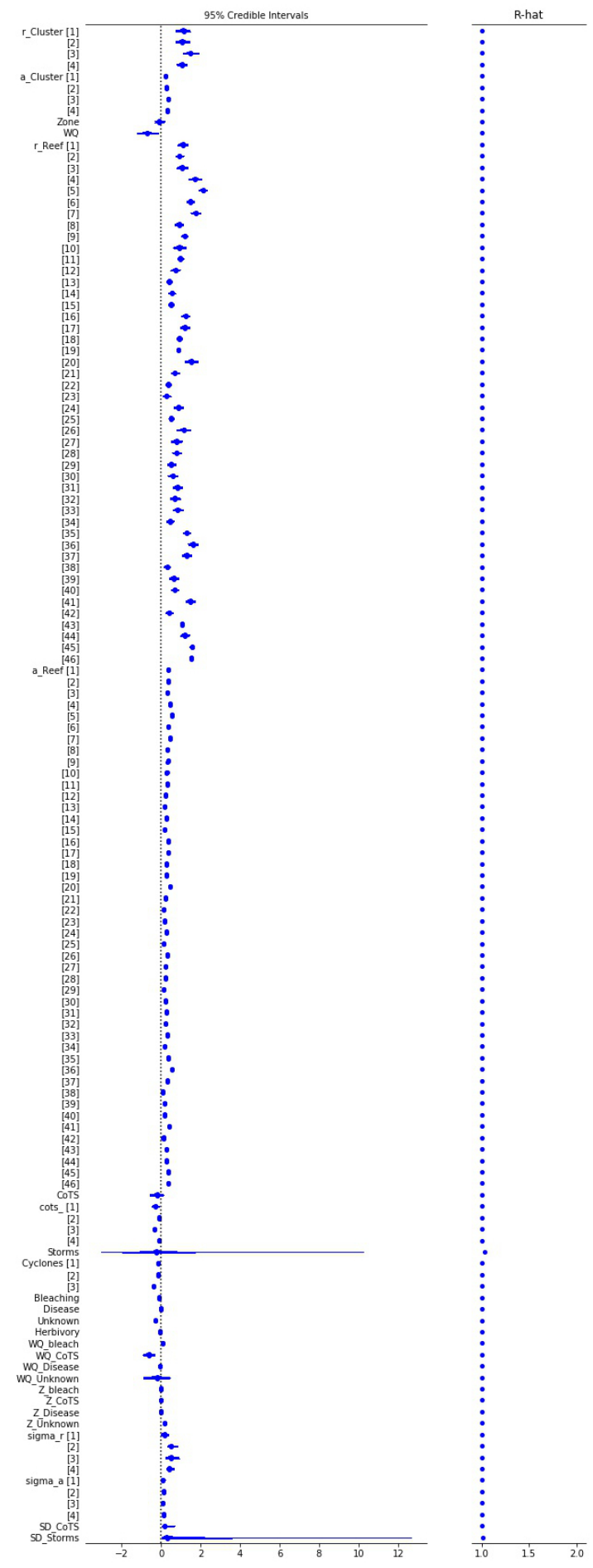
model of coral cover across the Great Barrier Reef. Underlying data are from 690 transects surveyed annually on 
46 reefs within the Australian Institute of Marine Science Long Term Monitoring Program 1995-2017. Note the Z in
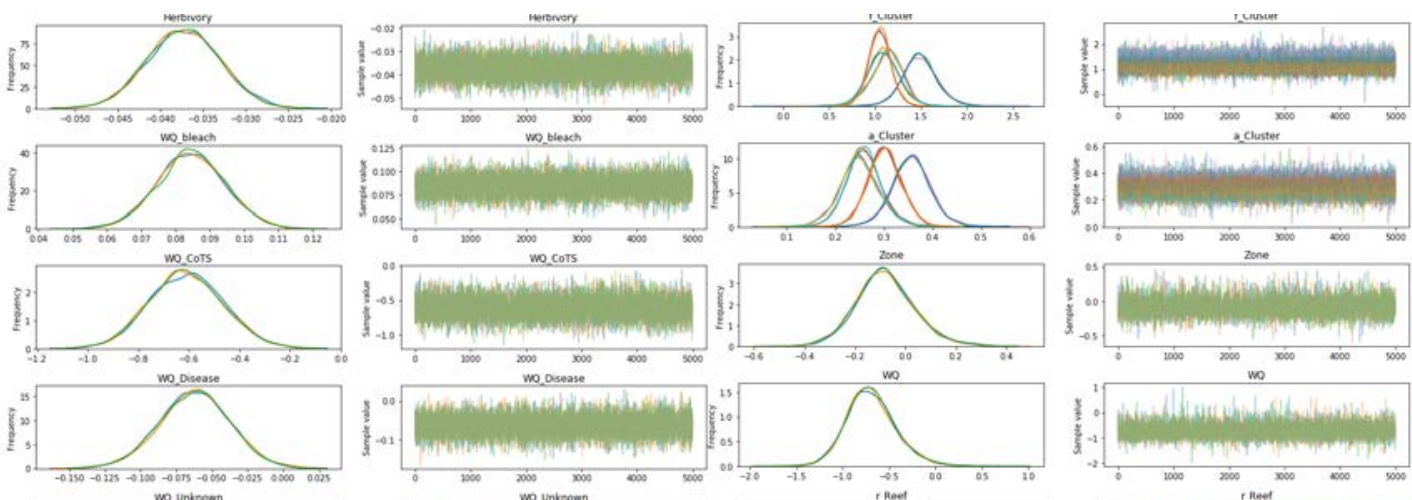

$\sum_{-05}^{\infty}$
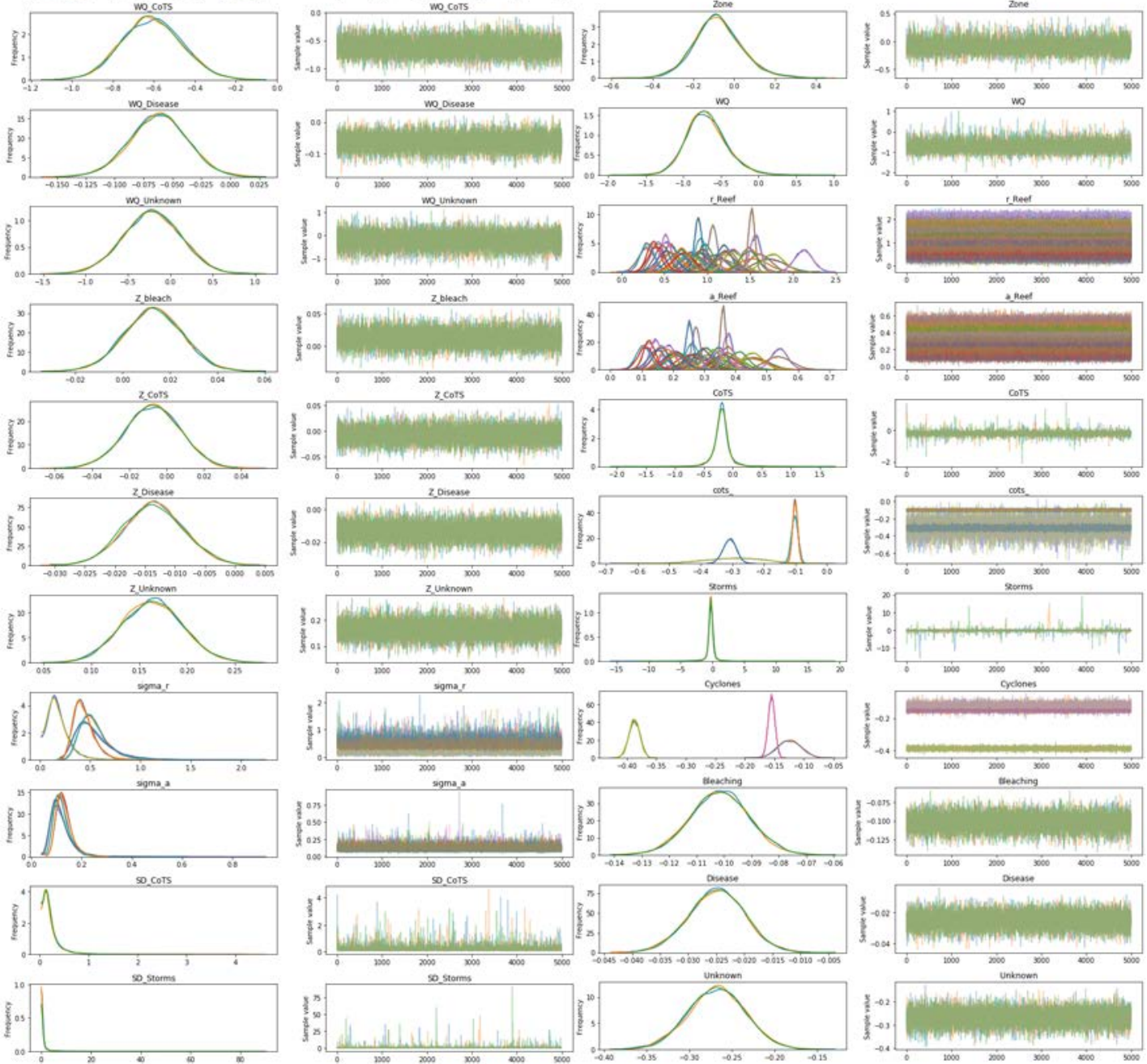

Extended Data Figure 3 | Posterior model diagnostics for a Bayesian hierarchical model of coral cover across

the Great Barrier Reef. Posterior forest plot of a) parameter estimates (posterior median, 50\% (thick line) and 95\% (thin line) uncertainty intervals) and b) Gelman-Rubin convergence statistics (R-hat) for a coral disturbance ( $>5 \%$ coral loss) probabilities from 690 transects surveyed annually on 46 reefs within the Australian Institute of Marine 

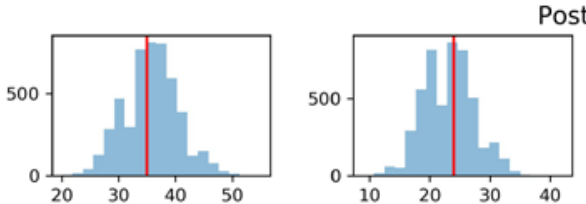

sterior predictive distributions
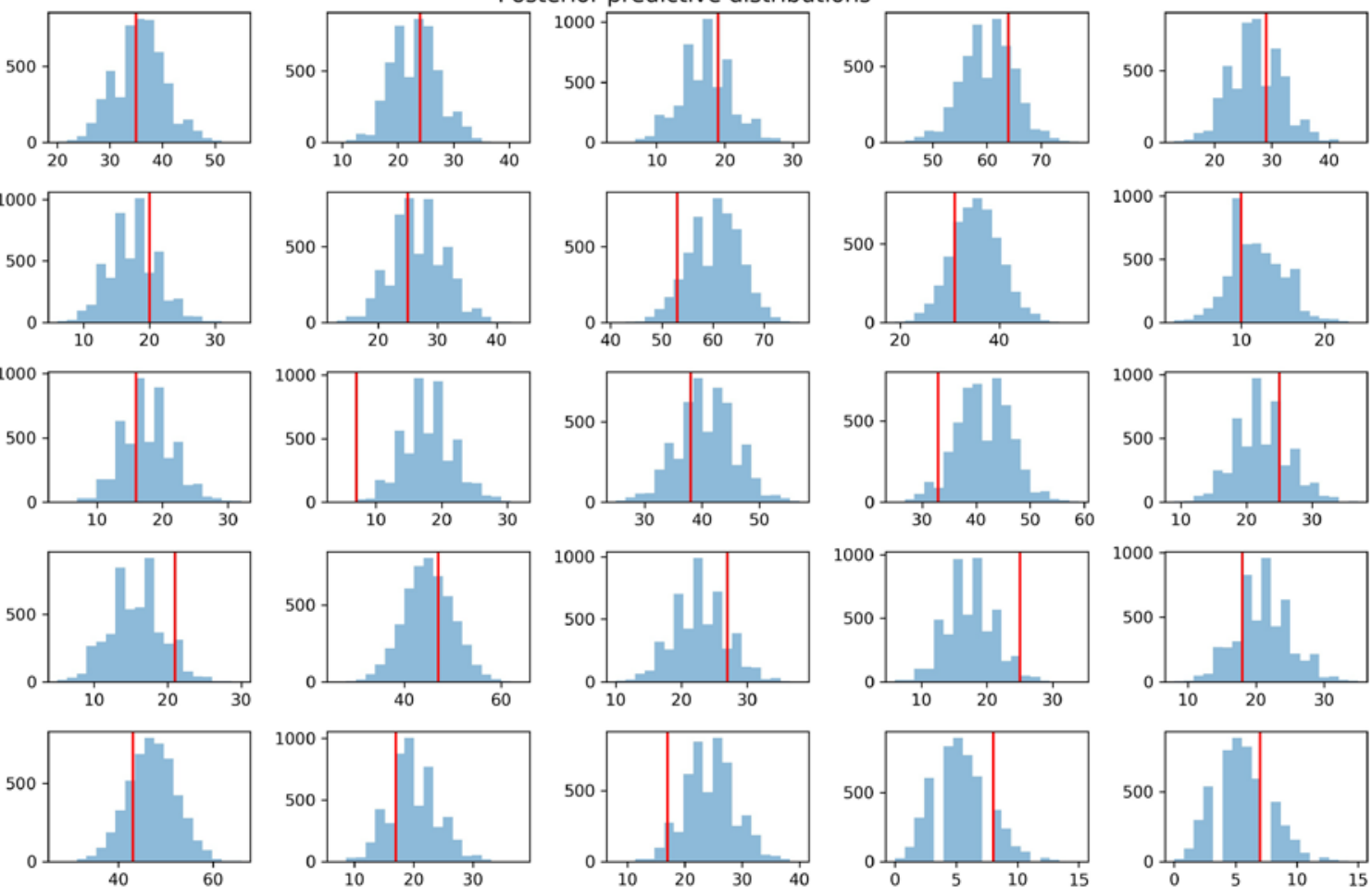

Extended Data Figure 4 | Diagnostic plots of model fit for a Bayesian hierarchical model of coral cover across

the Great Barrier Reef. Posterior predictive distributions (ppd; blue) of 25 random data points (red lines) for observed hard coral cover along the Great Barrier Reef. Relative correspondence between observed data and
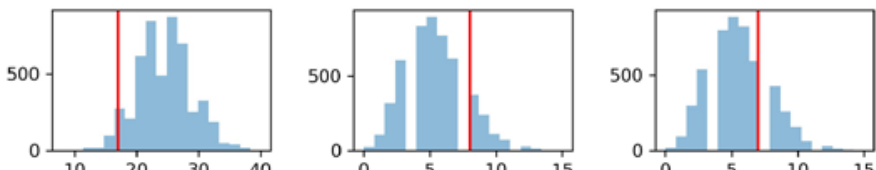
expected distribution given similar conditions (i.e. each ppd) is representative of adequate model fit. Red lines are beyond the 95\% highest posterior density of their predictive distribution are evidence of inadequate model fit for that datum. The Bayesian p-value for overall model fit was 0.56, providing no evidence of our model being inconsistent with the observed data. 


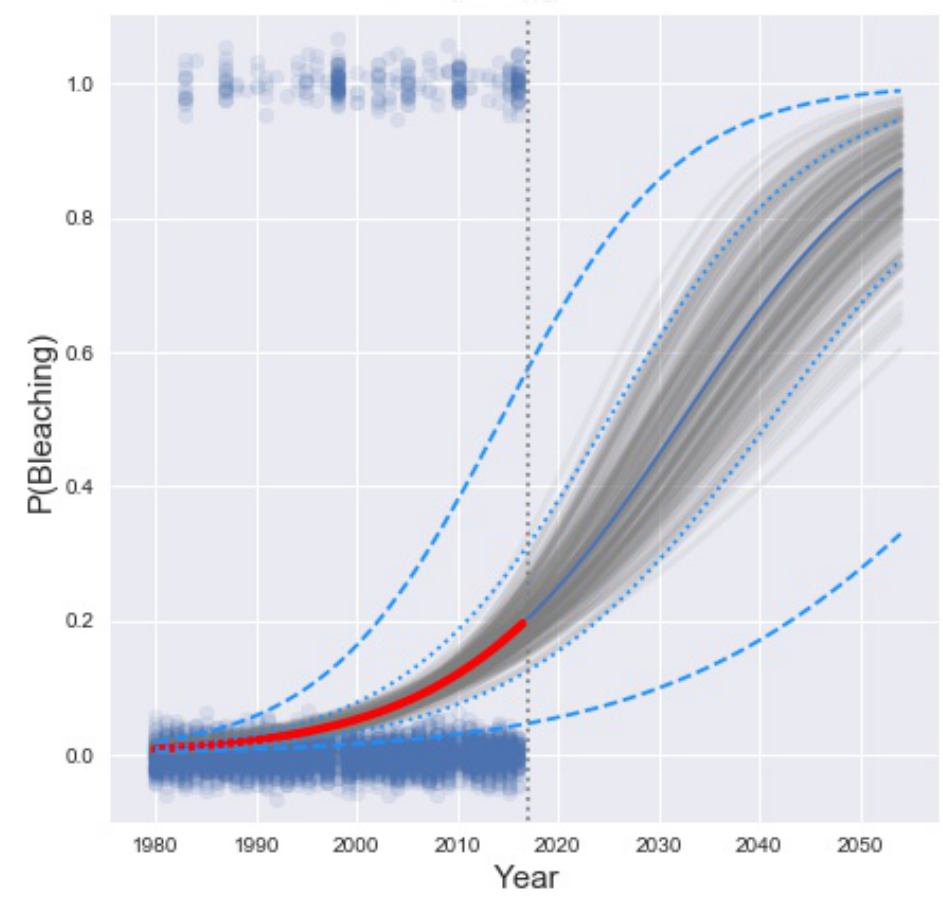

Extended Data Figure 5 | Estimated relationship of severe bleaching occurrences through time. Data (blue circles) extracted directly from supplemental table S1 of Hughes et al. $2018^{2}$, consisting of severe (S; $>30 \%$ bleached) coral bleaching records from 100 fixed global locations from 1980 - 2016. Estimated trend (red line) was estimated from a Bayesian generalized linear model of occurrences through time; plot includes $50 \%$ (dotted blue lines) and 95\% (dashed blue lines) uncertainty intervals for the predicted trend, as well as 100 realizations of the expected trend (grey lines) generated from the model posteriors. Solid blue trend line beyond the vertical dotted line was used as an empirically-based potential bleaching scenario in our future projections. 


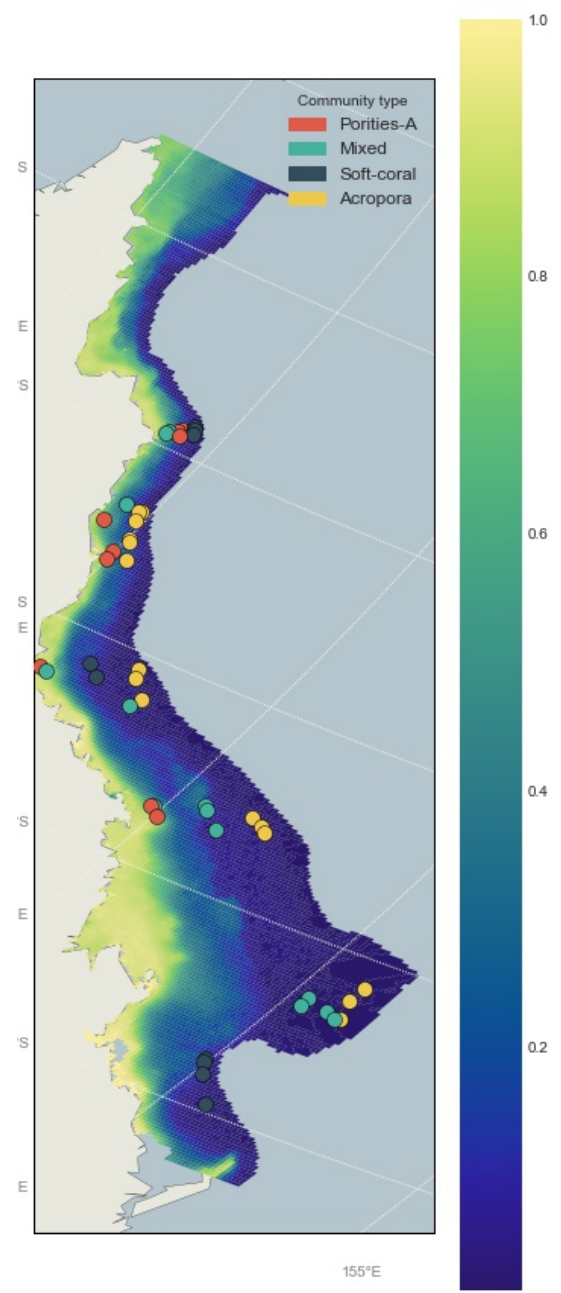

Extended Data Figure 6 | Derived index of average frequency of river-influenced plumes (PFc) across the Great Barrier Reef. Survey locations for AIMS long-term monitoring program (LTMP) reefs ( $\mathrm{n}=46)$ grouped by community type from Emslie et al. 2010 ${ }^{37}$. Index values are 0-1 scaled from combined primary (high turbidity and nutrients), secondary (high chlorophyll), and tertiary (high color dissolved organic material) waters, derived from MODIS true colour imagery from 2000 to 2014. 

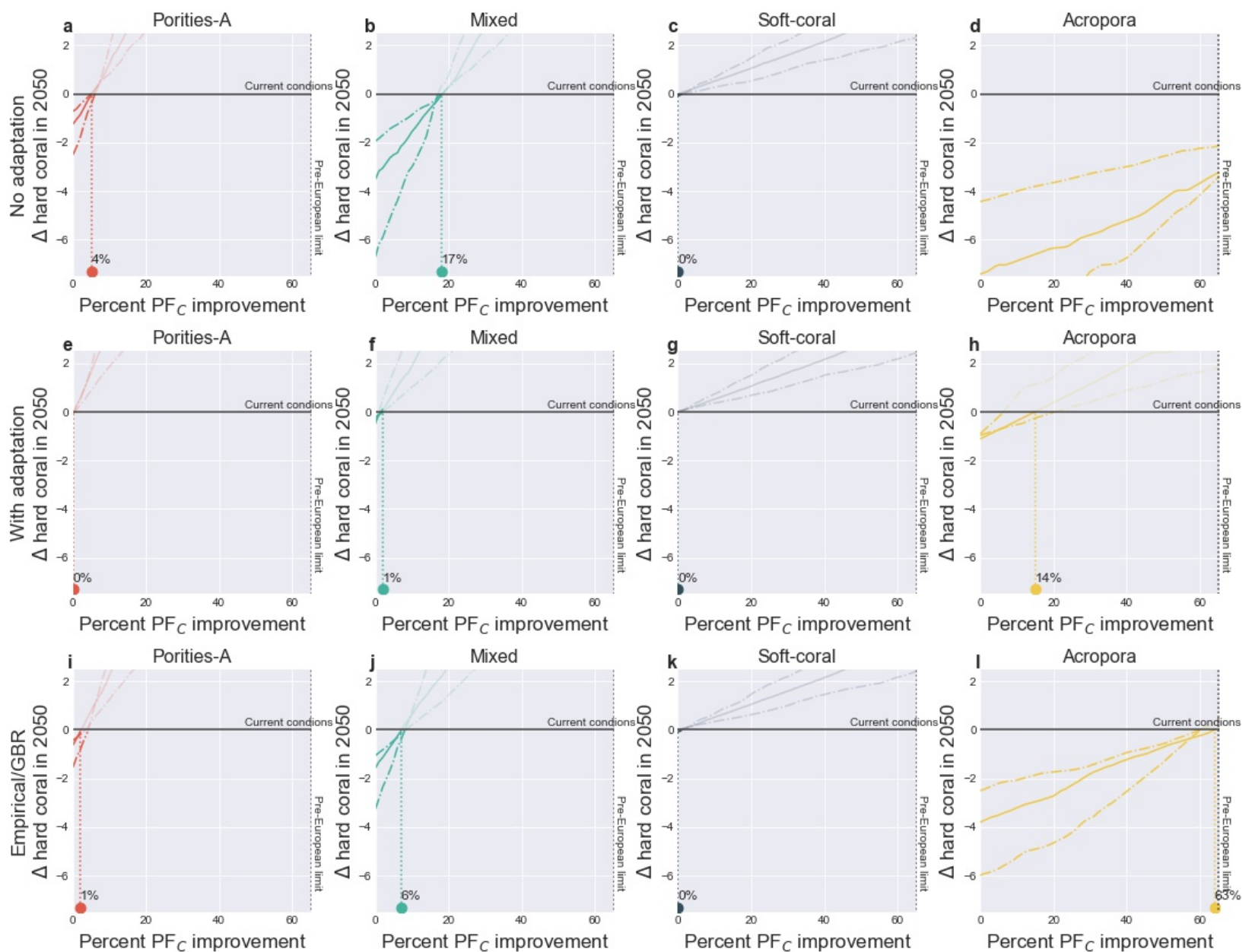

Extended Data Figure 7 | Approximate $50 \%$ uncertainty bounds for projected effects of changes in the average frequency of river-influenced plumes across the Great Barrier Reef, as represented in Figure 3.

Scenarios for increases in relative bleaching potential under RCP 4.5 (rows) given no adaptation, with a rolling 80 year window of adaptation ${ }^{13}$, and average expected GBR-specific trend from van Hooidonk et al. 2016 and the empirical trend estimated from Hughes et al. 2018. Projected net percent differences in median hard coral cover $(\Delta)$ relative to long-term expected coral cover under current disturbance conditions (i.e. no increase in frequency of bleaching-derived coral loss) given improvements in average water quality $\left(\mathrm{PF}_{\mathrm{C}}\right)$. Points along the $\mathrm{x}$-axis indicate level of $\mathrm{PF}_{\mathrm{C}}$ improvement necessary to counteract projected coral loss due to increases in the frequency of destructive bleaching. Pre-European limits (dotted line on far right) derived from estimates of proportion of anthropogenic influence. 